

\title{
Las Minorías Sexuales y la Investigación Urbana en la Ciudad de México (1960-2013)
}

\author{
As Minorias Sexuais e a Investigação Urbana na Cidade do México (1960- \\ 2013)
}

Sexual Minorities and Urban Studies in Mexico City (1960-2013)

\section{Resumen}

Este trabajo aborda las interacciones entre dos campos de estudio. Por un lado, se presentan las producciones académicas realizadas acerca de las minorías sexuales en la ciudad de México desde 1960, observando cómo han incorporado variables espaciales; y, por otro, de qué modo la investigación urbana ha integrado las sexualidades minoritarias como objeto de análisis. En la primera parte de este artículo, se describen los trabajos universitarios seleccionados, ilustrando el peso cada vez mayor de los aspectos geográficos en la comprensión de las prácticas e identidades sexuales minoritarias; mientras que, en la segunda, se ofrece una lectura de dichas referencias prestando atención a los debates y resultados que se vinculan con los procesos metropolitanos contemporáneos.

Palabras-Clave: Minorías Sexuales; Investigación Urbana; Género; Sexualidad; Ciudad de México.

\section{Resumo}

AAAs.

Palavras-Chave: Minorias Sexuais; Investigação Urbana; Gênero; Sexualidade; Cidade do México.

\begin{abstract}
This paper tackles interactions between two fields of study since the 1960's. On the one hand, it presents academic production about sexual minorities in Mexico City, in order to observe how it integrates spatial variables; on the other hand, it studies in which forms urban studies have incorporated sexual minorities as an object of analysis. The first part of this paper describes academic works that have been produced about sexual minorities and illustrates the increasing weight of geographic aspects in the understanding of their practices and identities; whereas the second part offers a reading of those references to pay attention to the discussions and results related to contemporaneous metropolitan processes.
\end{abstract}

Keywords: Sexual Minorities; Urban Studies; Gender; Sexuality; Mexico City. 


\section{Introducción}

En México, si bien la contribución de la geografía y de la investigación urbana al estudio de la sexualidad sigue todavía limitada, es cada vez más frecuente el uso de categorías espaciales para, desde las ciencias sociales y humanas, abordar la cuestión de las minorías sexuales. Los mismos títulos de las publicaciones, tales como 'Construcción de lugares gay', 'Al encuentro de la vida gay urbana', 'La identidad gay travesti, una lucha territorial'; reflejan un gran interés por aprehender la construcción individual y social de la sexualidad desde sus dimensiones espaciales. El giro espacial de las ciencias sociales en estas últimas décadas, junto con la influencia del feminismo, implicó una mayor referencia a las dimensiones geográficas de la construcción de la sexualidad y del género, así como la incorporación de conceptos espaciales en las investigaciones en ciencias sociales sobre minorías sexuales.

Ahora bien, la investigación geográfica sobre las minorías sexuales es todavía incipiente e insuficiente, mientras que las demás disciplinas tienden a centrarse en los modos de vida de los varones gays y, principalmente, en los lugares comerciales situados en las delegaciones centrales de la ciudad de México. La información sobre las geografías de las sexualidades minoritarias todavía no se ha integrado de manera sistemática y resulta difícil realizar análisis diacrónicos o longitudinales, por lo que existe poca continuidad entre las primeras etnografías sobre las formas de vida, los espacios de socialización y la construcción identitaria de las minorías sexuales en el pasado y las investigaciones más recientes. Mientras que, en los 70 y 80 , algunos antropólogos pioneros en el estudio de las sexualidades minoritarias en México, tales como Carrier (1976; 1989) en Guadalajara, o Taylor (1975; 1986) y Lumsden (1991), en la ciudad de México, señalaron algunos aspectos vinculados con el espacio urbano en la conformación de identidades sexuales modernas; al generalizarse el modelo gay internacional, la nueva generación abandonó este tipo de análisis, desligándose la reflexión del contexto local en el que las minorías sexuales construyen sus relaciones, prácticas e identidades.

En las líneas siguientes, a través del análisis de las referencias sobre las minorías sexuales publicadas desde 1960 en la ciudad de México, se busca observar cuándo y cómo se incorporó el espacio urbano en la investigación sobre las sexualidades minoritarias en la capital mexicana, para después esbozar una descripción de los principales ejes temáticos emergentes en la literatura y vincular así algunos de los resultados empíricos publicados sobre las minorías sexuales con los análisis de los procesos metropolitanos en este ciudad. Tras presentar, en la primera parte de este trabajo, una descripción de la metodología utilizada y de la bibliografía seleccionada, así como de las principales temáticas investigadas; en la segunda parte, nos enfocaremos en la incorporación de las minorías sexuales en los estudios urbanos; para finalmente señalar algunas dimensiones de la construcción socio-espacial de las sexualidades periféricas que se hallan vinculadas con las reflexiones contemporáneas de la investigación urbana. 


\section{Cincuenta años de invisibilidad. Las sexualidades periféricas en el campo académico de la ciudad de México}

\section{Búsqueda y selección de referencias}

Para realizar este trabajo, se consultaron publicaciones y revisiones de la investigación urbana sobre la ciudad de México para identificar las referencias que mencionan, dentro de este campo, a las minorías sexuales. Por otra parte, se llevó a cabo una búsqueda de referencias en los buscadores de las principales instituciones universitarias de la capital del país acerca de las sexualidades minoritarias, concentrándonos en los trabajos empíricos producidos por las ciencias sociales. Se seleccionaron únicamente los textos publicados en México entre 1960 y 2013, excluyéndose las ponencias y reseñas, así como las reflexiones meramente teóricas y los resúmenes. Tampoco se contemplaron los trabajos de sexología, psicología clínica, medicina y biología, ni se consultaron las revistas especializadas de pedagogía y psicología, pese al impacto que han tenido algunos de estos trabajos en la investigación y la comprensión de las minorías sexuales.

A través de una primera búsqueda por medio de distintas palabras claves ${ }^{1}$, se registraron los artículos de revistas académicas publicados sobre 'homosexualidad', 'bisexualidad' y modos de vida 'gay' en el catálogo de Consultas Latinoamericanas en Ciencias Sociales (CLASE) y en las publicaciones del Programa Universitario de Estudios de Género (PUEG), en la Universidad Nacional Autónoma de México (UNAM); así como en las revistas del Colegio de México, del Centro de Investigaciones y Estudios Superiores de Antropología Social (CIESAS), así como de las distintas unidades de la $\mathrm{UAM}^{2}$.

La segunda búsqueda se centró en las tesinas y tesis publicadas en la Escuela Nacional de Antropología e Historia (ENAH), la UNAM, la UAM, el Colegio de México así como el CIESAS. ${ }^{3}$ Además, se realizó otra búsqueda en

1 Se usaron los términos 'bisexual', 'gay', 'homosexual', 'homosexualidad', 'lesbiana', 'travestismo', 'transexual', 'travesti'. Empleo preferentemente 'minoría sexual', dado que la expresión 'diversidad sexual' tendría que abarcar, también, a los individuos que se definen como asexuales, así como a la mayoría heterosexual.

2 La búsqueda en la colección de publicaciones de la Revista Mexicana de Sociología fue realizada en la página de la revista para el período 2003-2013, y en la base JSTOR, para 19602003. En el Colegio de México, se consultó la dirección http://revistas.colmex.mx/. El contenido de las cinco revistas de ciencias sociales de la UAM-X fue consultado en http://148.206.107.15/dcsh/publicaciones/revistas.html. Consultamos el catálogo público de la Coordinación de Servicios de Información (COSEI), en la UAM-A., en http://cosei.azc.uam.mx/index.php/catalogo-publico/acervo-general.

3 Se consultaron los catálogos de la UNAM, disponible en http://www.metricas.unam.mx/TESIUNAM/index.php; del CIESAS (en www.ciesas.edu.mx); el repertorio de tesis digitalizadas del plantel de Iztapalapa de la UAM, disponible en tesiuami.izt.uam.mx, el catálogo de tesis digitalizadas del Colegio de México, en http://tesis.colmex.mx; así como el catálogo de la UAM-A, en http://espartaco.azc.uam.mx/ALEPH; así como en la web de la Especialidad y Maestría en Estudios de la Mujer, en: http://dcsh.xoc.uam.mx/estudiosmujer/nuev/buscador.html, además del catálogo general de la UAM-X. 
los catálogos generales de cada centro. Posteriormente, se incorporaron algunas obras solitarias o colectivas particularmente vinculadas con la problemática y se amplió la búsqueda con las palabras 'sexualidad', 'prostitución' y 'sexo' en algunos catálogos, añadiéndose trabajos publicados en revistas y editoriales universitarias o privadas que se referían a las sexualidades periféricas en la ciudad de México. ${ }^{4}$ Algunas de las nuevas referencias seleccionadas fueron leídas en su integralidad para determinar si hacían referencia a las minorías sexuales. Varias de ellas han sido producidas por académicos fuera del ámbito universitario, probablemente debido a la dificultad de publicar en el mismo: por ejemplo, List (2010) publicó, en la editorial LGBT Eón, su libro sobre 'El amor imberbe: el enamoramiento entre jóvenes y hombres maduros'. Por dicho motivo, dichas referencias no han sido incorporadas en al análisis, al no ser arbitradas.

Por otra parte, se seleccionaron revistas mexicanas de ciencias sociales con un fuerte vínculo con la investigación urbana, tales como la revista 'Cuidades, Análisis de la coyuntura, teoría e historia urbana', de la Red Nacional de Investigadores Urbanos (RNIU) y Benemérita Universidad Autónoma de Puebla (BUAP); o enfocadas al estudio del género, tales como 'Debate Feminista', de la UNAM. En total, se registraron 349 referencias. El 55\% (191) de las mismas constituyen tesinas de licenciatura y tesis de postgrado; el 29.5\% (103) son artículos; el 6.3\% (22) y el 9.5\% (33), respectivamente, son libros o capítulos de obras colectivas. Si excluimos los libros, capítulos y trabajos de fin de carrera (tesinas o tesis de licenciaturas, las cuales representan el $43 \%$ del total de publicaciones seleccionadas), para concentrarnos en artículos en revistas científicas y tesis de postgrado, meramente el $42 \%$ de estas referencias puede considerarse como trabajos arbitrados de investigación.

Así pues, en algo más de cinco décadas, solamente se produjo un promedio de tres trabajos empíricos al año que se refieren a las minorías sexuales en los principales centros universitarios de la ciudad de México. El peso del campo de estudio de las sexualidades minoritarias es, pues, insignificante en relación a la cantidad de publicaciones producidas en las instituciones académicas de la ciudad de México desde 1960. Además, la gran mayoría de los autores de las tesinas sobre dicha temática no vuelven a publicar después. No es hasta finales de los años 90 que algunos estudiantes, tales como Marinella Miano, Rodrigo Laguarda o Mauricio List, pudieron realizar una trayectoria académica centrada en el estudio de las minorías sexuales. La homofobia y el miedo a ser discriminado impusieron un techo de cristal para muchos otros, en un contexto en el cual escribir sobre sexualidades periféricas constituía un riesgo para su carrera universitaria y podía conducir al ostracismo, al igual que para los estudios feministas. (DE BARBIERI, 2004).

De ahí que, a mediados de los 90, la mayoría de los estudios empíricos sobre las minorías sexuales habían sido realizados por sociólogos y antropólogos extranjeros. Salvo algunas referencias provenientes de la investigación en salud pública y de la sexología -no incluidas en nuestra

4 El catálogo de tesis de la UAM-I, por ejemplo, se limita a los trabajos digitalizados y solamente se pueden realizar búsquedas por palabras del título y nombre del autor. Se buscaron por lo tanto referencias que tuvieran en su título dichos términos para consultar las tesis y verificar que trataran, aunque fuera en parte, de sexualidades minoritarias. 
selección-, hasta aquellas fechas, las publicaciones sobre las homo/bisexualidades en México habían sido publicadas en inglés en revistas extranjeras tales como 'Journal of Homosexuality', y es probable que las y los alumna/os de licenciatura de las universidades capitalinas no pudieran acceder con facilidad a estos primeros artículos, los cuales no suelen ser citados en las trabajos consultados. Mientras que los estudios de género estaban, por entonces, experimentando un proceso de institucionalización, con la apertura de distintos centros, programas de posgrado y seminarios dedicados a la crítica feminista y al estudio de la mujer en varios estados de la República, así como la publicación de números especiales en revistas académicas (MUÑIZ, 1997); hasta inicios de los años 2000, la investigación empírica sobre minorías sexuales que se llevaba a cabo en México se reducía a estudios de criminología y de psicología, a la realización de encuestas de seroprevalencia y estudios sobre los riesgos asociados a las conductas de los varones homo/bisexuales.

Gráfico 1. Evolución de las referencias académicas sobre las minorías sexuales en la ciudad de México según el tipo de publicación, 1964-20135.

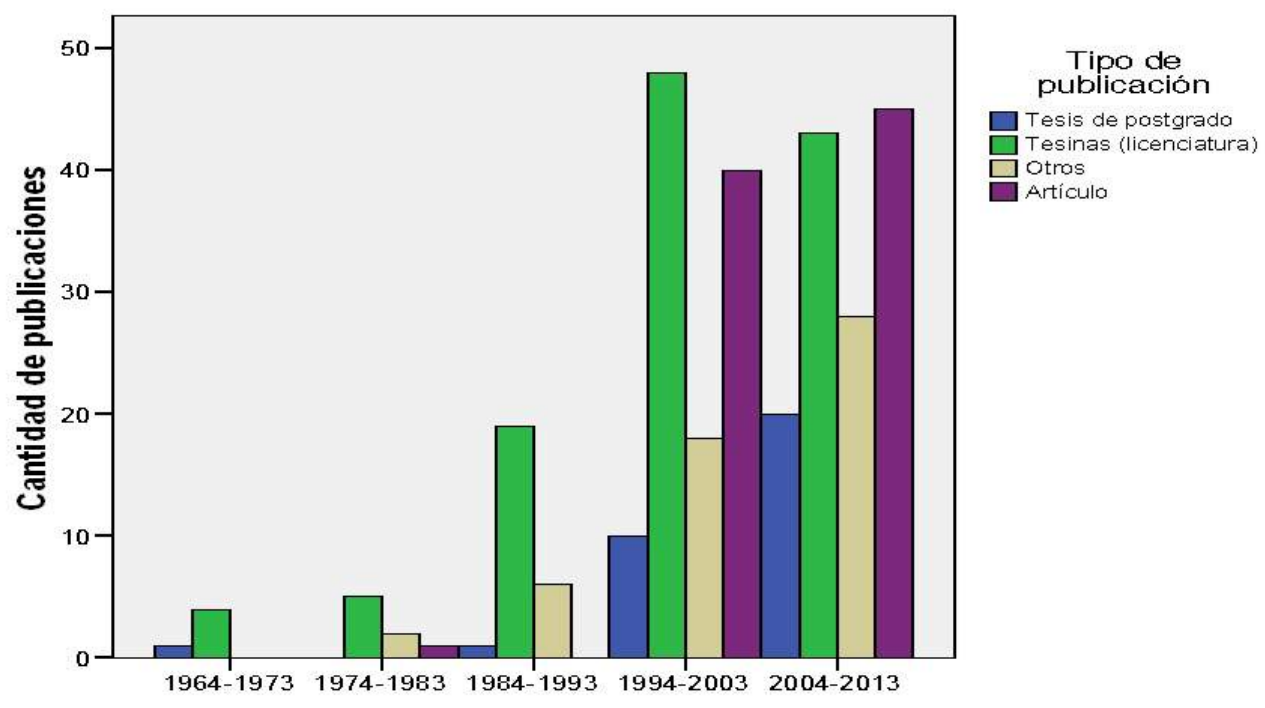

Fuente: Selección del autor, 1964-2013.

Tesinas y Tesis de Postgrado en los Principales Centros de la Ciudad de México

Respecto a los trabajos realizados por los estudiantes en los principales centros de la ciudad de México, el acervo seleccionado se compone en su gran mayoría (78\%) por tesinas; las tesis de maestría (16\%) y de doctorado $(6 \%)$ siendo más escasas y recientes. La primera tesis de licenciatura de la que tengamos referencia en el periodo analizado data del año 1966 y fue publicada en la Facultad de Psicología de la UNAM por Heredia, quien estudiaba el test de Rorschach para "detectar la homosexualidad", mientras que las siguientes tesinas tratan de la 'conducta sexual' y de la relación con la familia de los

5 La primera referencia encontrada desde 1960 data de 1966. Sin embargo, al dividirse en períodos de diez años, tuvimos que realizar el primer corte temporal en 1964. 
varones homo/bisexuales. Las primeras tesinas referenciadas en la UAMIztapalapa fechan de principios de $\operatorname{los} 80$, aunque es posible que se hayan publicado tesinas en la década anterior que no hayan sido incorporadas todavía a su colección de tesis electrónicas. Son más tardías en las demás unidades de la UAM: no es hasta finales de los años 90 que se halló las primera tesinas en la UAM-Xochimilco (FELICIANO, 1998) y la UAM-Azcapotzalco (GONZÁLEZ PÉREZ, 1999).

En cuanto a las tesis de posgrado, la primera tesis de maestría referenciada, 'El homosexual en México y su perfil criminológico', fue publicada en la Facultad de Derecho de la UNAM en 1987. La segunda tesis de este nivel fue defendida en la ENAH por Miano en 1992. En la UAM, no es hasta los inicios del siglo XXI que se censan las primeras tesis de posgrado: la primera tesis de maestría corresponde al trabajo de María Jesús González Pérez (2002) en la UAM-A. La primera tesis de doctorado, 'Estudio criminológico y médico legal de la homosexualidad', fue publicada en 1966 por José Antonio Ramos Frías en la Facultad de Derecho de la UNAM. Pero, hasta 1998, con la publicación, también en la UNAM, de la tesis de Norma Mogrovejo (1998) sobre el movimiento lésbico; no hemos encontrado otra tesis de doctorado en los centros universitarios de la capital. En la ENAH, el primer trabajo de este grado fue publicado por Miano (1999) y no es hasta fechas muy recientes que se publicaron trabajos de doctorado en el Colegio de México (GALLEGO, 2007) y la UAM (BARRANCO, 2008; ROSALES, 2006). ${ }^{6}$

La UNAM, la UAM y la ENAH, no sólo albergan los primeros trabajos sobre sexualidades minoritarias, sino que concentran la mayor cantidad de referencias, al representar el $43 \%$, el $19 \%$ y el $12 \%$, respectivamente, de las publicaciones, contra un 7\% y 4\% para el COLMEX y el CIESAS-DF. En los últimos años, se han publicado algunas tesis de postgrado y artículos en la Universidad Iberoamericana (LANZAGORTA, 2012) y el Instituto de Estudios Históricos Dr. Mora (ALMADA, 2004; BARRÓN, 2010; LAGUARDA, 2009), instituciones educativas consideras más conservadoras, lo que podría indicar una mayor legitimidad del objeto de estudio. En cambio, sólo se registraron tres tesis de maestría en el catálogo del CIESAS, y los trabajos de postgrado son escasos y más recientes en el Colegio de México.

De hecho, en el catálogo de dicha institución, no figura ningún título con los términos 'homosexual' o 'gay', dado que el alumnado con frecuencia utiliza elipsis para evitar emplear términos que se refieran directamente al sexo y a los vínculos afectivos entre personas del mismo sexo. Por consiguiente, se consultó el catálogo de la Maestría en Estudios de Género del Programa Interdisciplinario de los Estudios de la Mujer (PIEM): de 61 registros existentes desde la primera promoción en 2003 hasta 2013, 50 consisten estudios de la mujer, 5 tratan de masculinidad heterosexual, y meramente 4 se enfocan en varones gays y otros hombres que tienen sexo con hombres (HSH) y 2 tratan de mujeres lesbianas o bisexuales.

6 Son menos numerosas las referencias en la UAM-X, incluso en el Programa de Estudios de la Mujer, en donde, de 80 tesis de maestría realizadas entre 2002 y 2013, sólo dos trataban de minorías sexuales. Es probable que entre los años 1960 y 1990, al no ser obligatoria la obtención de un grado para llevar a cabo actividades docentes, fueran menores los egresados de maestrías y doctorado en la ciudad de México. 


\section{Disciplinas en el Estudio de las Minorías Sexuales: La Invisibilidad de la Geografía}

El resultado de nuestra búsqueda bibliográfica evidencia que la disciplina predominante en la difusión del conocimiento en torno a las sexualidades periféricas es la antropología. ${ }^{7}$ Un total de 84 publicaciones, es decir, el 24\% de nuestra selección, ha sido redactado por antropólogos y otro $16 \%$ por especialistas en estudios culturales e históricos. Sin embargo, durante muchos años predominó la psicología y la psicología social, que representan el 18\% de las publicaciones, lo que implica un papel importante de dichas disciplinas en la definición del objeto de estudio. En contraste, la geografía meramente representa el 3\% del total de publicaciones referenciadas; ausencia que solamente se rompió a principios del siglo XXI. (Tabla 1).

Tabla 1. Referncias por Disciplinas del aútor sugun el tipo del publicación, 1960 - 2013.

\begin{tabular}{|c|c|c|c|c|c|}
\hline Disciplina & Artículos & $\begin{array}{c}\text { Libros y } \\
\text { Capitulos } \\
\text { de Obras } \\
\text { Colectivas }\end{array}$ & Tesina & $\begin{array}{c}\text { Tesis de } \\
\text { Postgrado }\end{array}$ & Conjunto \\
\hline Antropologia & $43 \%$ & $30 \%$ & $7 \%$ & $31 \%$ & $24 \%$ \\
\hline Psicologia & $9 \%$ & $11 \%$ & $29 \%$ & $10 \%$ & $18 \%$ \\
\hline $\begin{array}{c}\text { Historia y Estudos } \\
\text { Culturales }\end{array}$ & $17 \%$ & $35 \%$ & $11 \%$ & $12 \%$ & $16 \%$ \\
\hline Sociologia & $23,0 \%$ & $17 \%$ & $11 \%$ & $17 \%$ & $16 \%$ \\
\hline Derecho & $0 \%$ & $2 \%$ & $26 \%$ & $7 \%$ & $12 \%$ \\
\hline $\begin{array}{c}\text { Estudios Políticos y Ciencias } \\
\text { de la Comunicacion }\end{array}$ & $2 \%$ & $4 \%$ & $13 \%$ & $14 \%$ & $8 \%$ \\
\hline $\begin{array}{c}\text { Geografia y Estudios } \\
\text { Urbanos }\end{array}$ & $6 \%$ & $0 \%$ & $2 \%$ & $0 \%$ & $3 \%$ \\
\hline Medicina Legal/Social & $1 \%$ & $2 \%$ & $1 \%$ & $5 \%$ & $2 \%$ \\
\hline Criminologia & $0 \%$ & $0 \%$ & $0 \%$ & $5 \%$ & $1 \%$ \\
\hline Total & $\mathbf{1 0 3}$ & $\mathbf{5 4}$ & $\mathbf{1 4 8}$ & $\mathbf{4 2}$ & $\mathbf{3 4 7}$ \\
\hline
\end{tabular}

Fuente: Selección del autor.

Mientras que la psicología representa el $25 \%$ de las tesinas y el $9 \%$ de las tesis de posgrado publicadas, un $43 \%$ de los artículos encontrados acerca de las sexualidades periféricas han sido escritos por antropólogos. Tras el artículo pionero de Noemí Quezada (1979) publicado en 'Anales de Antropología', de

7 Se tiene que tomar en consideración el sesgo ligado a la misma selección de las publicaciones analizadas, dado que se excluyeron revistas especializadas de sexología, psicología, medicina y educación, en las cuales hubiéramos encontrado más referencias. 
la UNAM -seguido de una relativa ausencia durante dos décadas ${ }^{8}$, 'Cuicuilco', revista de la ENAH, que aglutina el 18\% de las publicaciones, junto con otras revistas de antropología tales como 'Debate Feminista' (14\%) y 'Desacatos' (13\%), constituyen las principales revistas académicas con artículos sobre sexualidades minoritarias. En cambio, las revistas de sociología fueron y siguen siendo más tímidas a la hora de abordar la temática, al igual que las revistas de geografía e investigación urbana..

Tabla 2. Percentaje de Publicaciones sobre Minorias Sexuales en Revistas Académicas, 1960 2013.

\begin{tabular}{|c|c|}
\hline Nombre de la publicación & $\begin{array}{c}\text { Porcentaje (\%) del } \\
\text { total de } \\
\text { publicaciones }\end{array}$ \\
\hline Cuicuilco (UAM - Azcapotzalco) & $18 \%$ \\
\hline Debate Feminista (UNAM-PUEG) & $14 \%$ \\
\hline Desacatos (CIESAS) & $13 \%$ \\
\hline Ciudades (Red Nacional de Investigación Urbana - \\
BUAP) & $7 \%$ \\
\hline El Cotidiano (UAM - Azcapotzalco) & $5 \%$ \\
\hline Revista Mexicana de Sociologia (UNAM) & $5 \%$ \\
\hline $\begin{array}{c}\text { Estudios Demográficos y Urbanos (Colégio de } \\
\text { México) }\end{array}$ & $4 \%$ \\
\hline Sociológica (UAM - Azcapotzalco) & $3 \%$ \\
\hline Revista de Estudios de Antropologia Sexual (UAM - & $3 \%$ \\
\hline Azcapotzalco) & $3 \%$ \\
\hline Alteridades (CIESAS) & $21 \%$ \\
\hline Otras Revistas & $\mathbf{1 0 3}$ \\
\hline Total & \\
\hline
\end{tabular}

Fuente: Selección del autor.

Al hallarse pocos artículos con los términos 'lesbiana', 'gay' y 'homosexual' en el catálogo digital del COLMEX, se amplió la búsqueda mediante la palabra 'sexualidad', tanto en el campo 'materia' como en el título del mismo. Se encontró así un total de 31 registros, pero sólo 6 de dichas publicaciones se refieren a las minorías sexuales, destacando los trabajos sobre el VIH-sida. En las 5 revistas de sociología y ciencias políticas de la UAM-X, en todo el período no se encontró más que 6 referencias que mencionan las sexualidades minoritarias. Finalmente, la 'Revista Mexicana de Sociología', la primera revista de ciencias sociales en América Latina, para el periodo de 1960-2003,

8 En los 80, el único artículo que se localizó sobre dicha temática es una reflexión teórica de Xabier Lizárraga (1980), profesor de antropología física en la ENAH, publicada en Cuicuilco. 
salvo la publicación las reflexiones de Carl Zimmerman sobre 'las prácticas sexuales de la intelligentsia', en 1963, en donde el autor presentaba la homosexualidad como un peligro para la integración familiar; hasta 2003, no publicó ningún trabajo empírico sobre minorías sexuales. El primer título se encontró con la palabra clave 'sexualidad' en 2003 y, desde entonces, la Revista Mexicana de Sociología sólo publicó 5 referencias acerca de las minorías sexuales, 3 de ellas en un mismo volumen, lo cual pone de manifiesto el profundo desinterés de aquella revista por dicha temática.

El gráfico 2 permite observar la evolución, a lo largo de medio siglo, de las disciplinas predominantes en el abordaje de las homo/bisexualidades, travestismo y transexualidad en la ciudad de México, distinguiéndose varios períodos. Observamos que, entre mediados de los años 60 y principios de los 90, destacaban por su elevado número los trabajos de psicología o psicología social. A finales de los 80 se publican varias tesis en el departamento de sociología de la UAM-I y, ya para mediados de los 90, la antropología, la historia y los estudios culturales empiezan a predominar en la investigación sobre minorías sexuales; mientras que la criminología va siendo sustituida por trabajos sobre los derechos humanos de las personas LGBTT así como investigaciones en ciencias políticas y de la comunicación. Según observamos en el gráfico 2 siguiente, la geografía y los estudios urbanos se incorporan tardíamente en el estudio de las minorías sexuales.

Gráfico 2. Porcentaje de publicaciones por disciplina según el periodo.

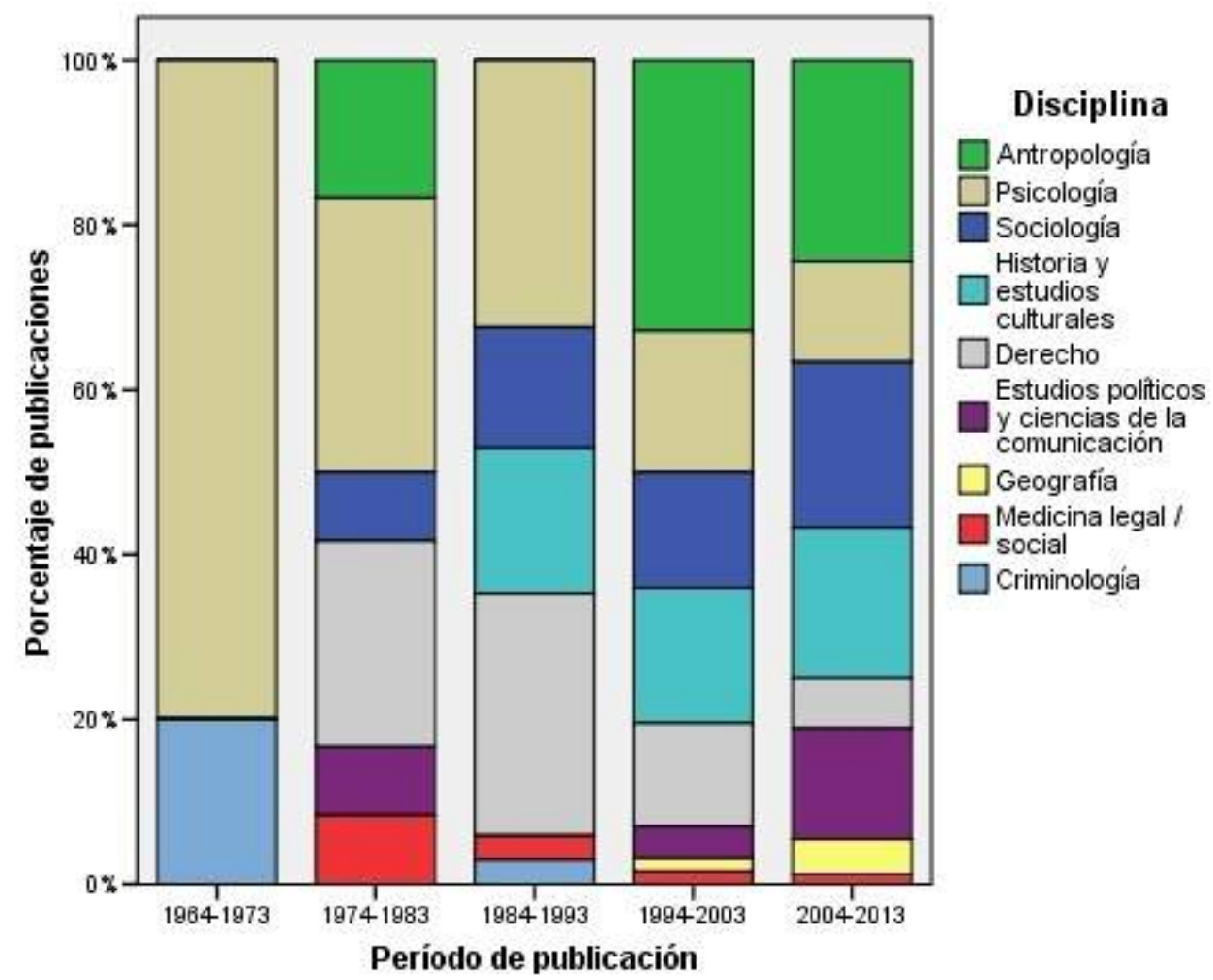

Fuente: Selección del autor. 


\section{Temáticas y Enfoques de las Publicaciones Académicas}

Con el objetivo de realizar un análisis temático de las referencias sobre minorías sexuales en México, agrupamos las referencias en diez grandes grupos. El más importante de ellos reúne las referencias que se enfocan en la construcción cultural y socio-histórica de las sexualidades minoritarias, con un $19 \%$ de las publicaciones; seguido por el segundo grupo, acerca de los modos de vida y la geografía de los lugares de ocio, socialización y encuentro, con un $14 \%$ de las referencias seleccionadas. Un $10 \%$ se centra en el estudio de movimientos LGBT y políticas públicas; otro $10 \%$ constituye análisis de la situación jurídica y, después, los derechos humanos de las minorías sexuales; mientras que un $9 \%$ de las publicaciones se enfoca en salud sexual, prevención y VIH/SIDA y el 9\% trata de estigma y discriminación. Los demás temas, tales como pareja y matrimonio, o adopción, entre personas del mismo sexo, cambio de nombre y trabajo sexual, surgen más recientemente y son menos estudiados.

Gráfico 3. Cantidad de publicaciones por enfoque temático según grandes períodos, 19642013.

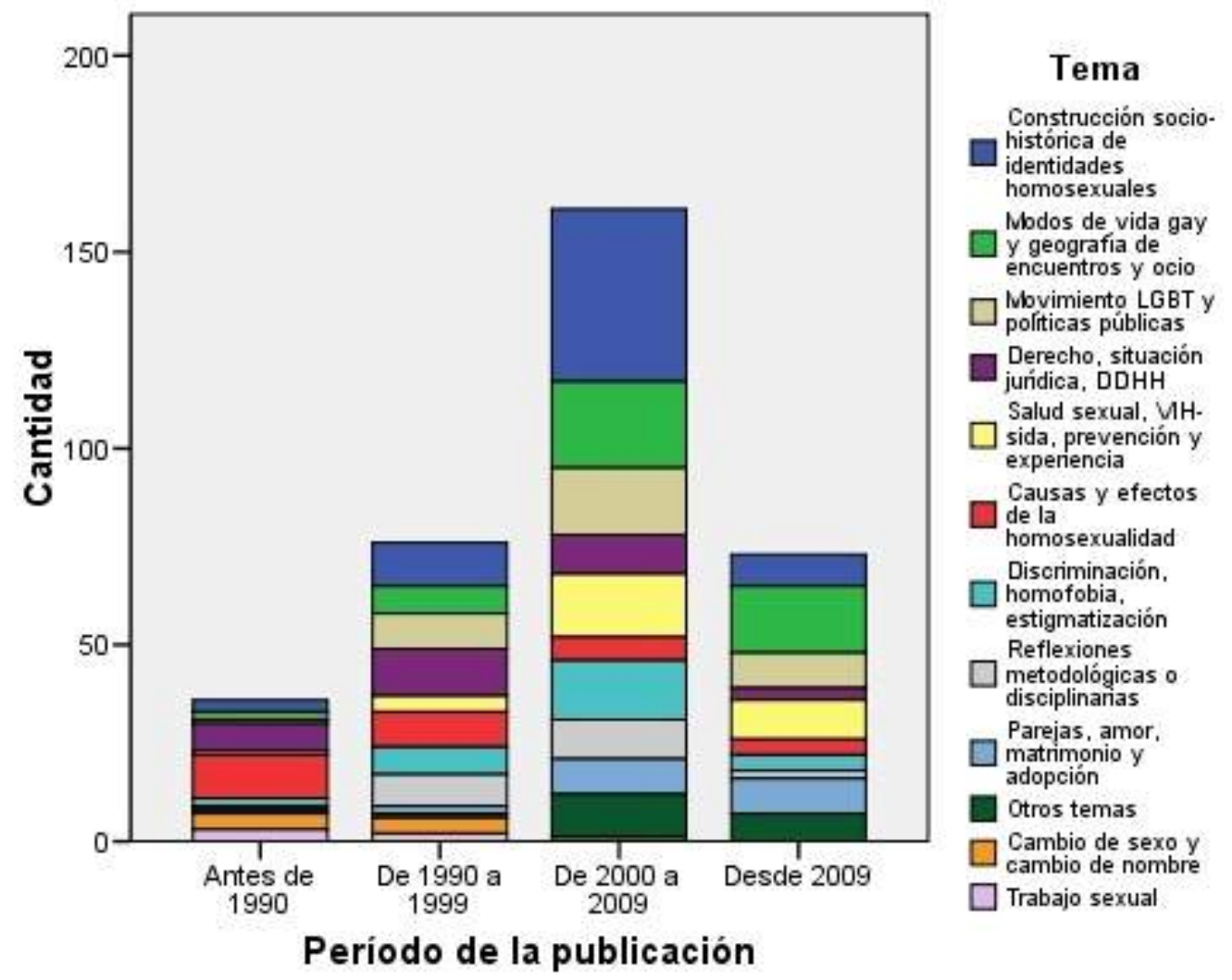

Fuente: Selección del autor, 1964-2013.

Cronológicamente, la investigación se ha centrado primero en las causas y los efectos psicosociales ligados a las identidades y prácticas sexuales minoritarias (con un 6\% del total de las referencias); para, en los años 1980, abordar el movimiento LGBT y las políticas públicas hacia las minorías sexuales; mientras que, a partir de finales de dicha década, el VIH/SIDA supuso la incorporación de las temáticas vinculadas con la salud sexual y la 
prevención de enfermedades de transmisión sexual entre las poblaciones LGBT. Desde principios del siglo XXI, se multiplican las temáticas.

El debate sobre las causas y efectos de la homosexualidad y de la transexualidad se halla presente desde los años 60. Si bien, en los 70, inspirados por el surgimiento del movimiento homosexual y de la sexología al nivel internacional, algunos trabajos replantean el objeto de estudio desde la psicología social, interrogándose sobre los 'aspectos biosociales y psicológicos' (SÁNCHEZ HUESCA, 1970) o 'clínico-sociológicos' (RIVERA, 1975) del homoerotismo, y redefiniendo la homosexualidad como una 'forma de expresión sexual, social y cultural' (VILLA, 1975); durante mucho tiempo se han mantenido algunos modelos, conceptos y preceptos provenidos del conductismo y de la criminología, que han permeado hasta la actualidad en los trabajos de psicología social y de derecho, e incluso de sociología.

Así, en los 80, las y los estudiantes todavía consideraban que las sexualidades periféricas constituían una 'aberración sexual' (MORENO, 1983; PERCASTRE, 1989); mientras que en los 90 siguieron publicándose tesinas que definían la homosexualidad como una 'desviación sexual' (BARRALES, 2005; GARCÍA ALFARO, 2009; GARCÍA, 1999), equiparable al adulterio (Martínez, 1994), al abuso sexual contra menores y a las 'conductas antisociales' (CRUZ HERNÁNDEZ, 1993). Por ejemplo, en su tesina de sociología sobre 'La homosexualidad como fenómeno social: marginación y actitud de rechazo social', cuyo 'objetivo e interés' era recabar "información más clara sobre lo qué es el homosexualismo (sic) para reducir la hostilidad social", Sandoval sugiere algunas "medidas recomendadas a adoptar para la prevención y evitar [su] propagación". La educanda explica incluso que "en ocasiones el matrimonio es la forma convencional de ocultar [una] tendencia sexual anómala" (SANDOVAL, 1990, p. 6).

De un modo similar, para establecer la homosexualidad del conyugue como causal de divorcio, Barrales explica que "el transexualismo", concebido como "el cambio físico de sexo a consecuencia del deseo de la persona de pertenecer al sexo contrario, que llega a grado tal de intervenirse quirúrgicamente", conlleva la "imposibilidad de llevar a cabo con su conyugue una relación sexual convencional" y la falta de compromiso ante los deberes matrimoniales (BARRALES, 2005, p. 184). Según el estudiante de psicología, "la homosexualidad, el lesbianismo (sic) y la bisexualidad", a su vez, ponen fin a toda relación marital, "además del impacto emocional que sufre la pareja inocente como víctima". (BARRALES, 2005, p. 187). Si bien admiten que existe una gran diversidad de "tipos de homosexuales", quienes pueden incluso estar casados con una mujer y tener hijos; los estudiantes asocian homosexualidad con enfermedad o delincuencia; niegan la posibilidad de la bisexualidad, expresando una serie de prejuicios todavía muy establecidos en las instituciones de salud (GARCÍA MURCIA et al., 2010).

La pervivencia, en las publicaciones sobre los orígenes y los efectos psicosociales de la homosexualidad y de la transexualidad, de algunos prejuicios hacia las minorías sexuales, fue reforzada por el paradigma biomédico que se generalizó en los estudios sobre sexualidad y VIH/SIDA en México a finales de los 80 . Parker afirma que hasta bien avanzada la década de los 90, en América Latina, dicho paradigma se caracterizaba por "un gran 
prejuicio individualista en relación a las maneras en que las ciencias sociales podrían contribuir de manera significativa al desarrollo e implementación de una agenda de investigación sobre el VIH/SIDA" (PARKER, 2010: 86-87), mientras que Héctor Carrillo recordaría, a mediados de los años 90, la falta de "estudios etnográficos en torno al VIH/SIDA en los que se tomaran en cuenta los significados asociados al sexo, la sexualidad y las relaciones interpersonales". (CARRILLO, 2002 [1996], p. 27). Por consiguiente, si bien el surgimiento del VIH/SIDA implicó un impulso de la investigación sobre las minorías sexuales (LIGUORI, 1995), al mismo tiempo contribuyó a la perpetuación del paradigma biomédico y fomentó la comprensión de la homosexualidad y de la bisexualidad como problema de salud pública: "La homosexualidad en los tiempos de SIDA se convirtió en un doble estigma, a tal grado que ser homosexual y seropositivo se asimiló como términos sinónimos”, explica así Feliciano $(1998$, p. 7$)$ en su tesis de licenciatura.

\section{Multiplicación de Enfoques y Diversificación de las Temáticas}

El surgimiento del VIH y la mayor colaboración entre militantes, artistas o empresarios LGBT en la lucha contra el SIDA, junto con las nuevas prácticas y discursos por parte de los mismos en relación al sexo entre personas del mismo sexo, así como la incorporación de los estudios de género y el enfoque feminista en las ciencias sociales (OROZCO, 2010); impulsó la realización de trabajos sobre sexo entre varones y masculinidades periféricas, contribuyendo a precisar y complejizar las categorías, así como a modificar las metodologías de acercamiento y análisis de las realidades de las minorías sexuales. Esta diversificación de las temáticas y enfoques es perceptible en la multiplicación de trabajos sobre el amor, la pareja, el matrimonio y la adopción entre personas del mismo sexo (CRUZ, 1998; ESCOBEDO, 2011; LEÓN, 2010); los derechos humanos de las minorías sexuales (CORONADO, 1996), así como sus modos de vida (BALBUENA, 1997; NAVARRETE, 1997), lo que a su vez conllevó un mayor interés por los espacios de socialización y construcción de las sexualidades minoritarias.

A principios del siglo XXI se hizo cada vez más necesaria la integración de las metodologías etnográficas para dar una respuesta adecuada al VIH (BRONFMAN, 1999). No sólo perdieron validez las asunciones de la psicología como base para los programas de prevención, sino que fue afirmándose más nítidamente la necesidad de tomar en cuenta el conjunto de factores estructurales y culturales que intervienen en la construcción de la diversidad sexual; confirmándose la importancia de considerar los estigmas y la discriminación hacia las minorías sexuales (MIRANDA, 2004; PACHECO, 2002; RUBIO, 2003).

Los universitarios se enfocaron con mayor frecuencia en los discursos y prácticas de los propios agentes acerca de sus relaciones sexuales y afectivas, generando nuevos modos de aproximación a la realidad vivida por las minorías sexuales y centrándose en los discursos y representaciones de los sujetos. De

9 El $46 \%$ de las referencias se publicó en dicho período, mientras que un $11 \%$ lo antes de 1990 , contra $22 \%$ entre el año 2000 y 2009 , para disminuir desde entonces. 
ahí el nuevo papel que adquirió la antropología a lo largo de los años 90 para analizar "los contextos culturales dentro de los cuales la conducta toma lugar -y hacia los símbolos y significados culturales, y hacia las reglas que los organizan" (PARKER, 2010, p. 88).

Para finales del siglo XX, la investigación antropológica no sólo "redescubriría" la sexualidad como objeto de estudio, según la expresión de Carol Vance (1997); sino que la misma empezó a dar cuenta de una diversidad de modos de vida y expresión de las minorías sexuales en México. El interés por las causas y los efectos de las sexualidades periféricas fue sustituido por el estudio de la construcción social, cultural e histórica de las identidades sexuales, en especial en el período 2000-2009, es decir, en un momento de auge de la producción académica sobre minorías sexuales ${ }^{9}$, abandonándose el conductismo. Esta integración de disciplinas y perspectivas dio lugar al surgimiento de nuevas líneas de investigación, tales como el derecho a la salud de las minorías sexuales o el cambio de sexo y de nombre de las personas transexuales. Es así cómo, en los años 2000 también se multiplicaron los estudios sobre los espacios de socialización de las minorías sexuales.

A principios del siglo XX, Miano y Giglia (2001, p. 90) afirmarían incluso que la "cuestión gay" se había normalizado y que había perdido su connotación revolucionaria: "ahora designa una forma de ser y un estilo de vida". Esta visión se imprimiría en muchas de las publicaciones llevadas a cabo por los estudiantes y académicos de los centros universitarios capitalinos. Desde principios del siglo, se entiende en efecto que "más que una emisión de acciones de un individuo encaminadas a buscar respuesta en otro" o "el comportamiento característico resultante de la atracción y relación entre personas del mismo sexo", la homosexualidad constituye "un estilo de vida que podemos aprehender mediante lo que denominamos elementos de identidad", explica Díaz Barber del Toro (2001, p. 28), ilustrando un cambio de perspectiva en la aprehensión de las sexualidades minoritarias, a la vez que cierta dificultad para dejar atrás algunos prejuicios académicos acerca del llamado comportamiento homosexual.

Pese a esta visión más relativista, a partir de finales del siglo $\mathrm{XX}$ y principios del XX, muchos trabajos publicados (HERNÁNDEZ, 2001; LIZÁRRAGA, 2003; LIST, 2000; NAVARRETE, 1997; ÁVALOS, 2007; entre otros) buscan integrar la historia mexicana de las homosexualidades en el marco universal del desarrollo de las mismas hasta la emergencia del movimiento gay, tanto para rehabilitar y normalizar las sexualidades periféricas, como para fortalecer un campo de estudio en la capital mexicana. Suelen dedicar un capítulo específico al relato de la "historia universal de la homosexualidad" y al surgimiento de una identidad sexo-política homosexual en el continente europeo del siglo XIX, con los anacronismos que esto implica. (Véase, por ejemplo, PALMA, 2007). Los autores tratan así de evidenciar que la "homosexualidad" es un fenómeno natural por su presencia reiterada en la historia de la humanidad. "En el transcurso de diversas etapas históricas y culturales existe una visible muestra de conductas homosexuales", asegura por ejemplo Martínez (2012, p. 2) en su trabajo sobre la Marcha LGBT. Las y los estudiantes buscan así justificar su objeto de estudio, lo que incidirá en el empleo de la expresión "diversidad sexual", cuyo sentido a menudo excluye a 
las diversas heterosexualidades, e incluso a las bi/homosexualidades que no participan del actual y predominante modelo lésbico-gay.

\section{El Género y los Estudios sobre Sexualidad en México}

Pero la investigación sobre las minorías sexuales no meramente ha sido alentada por la urgencia sanitaria y el abandono de los enfoques individualistas y conductistas, como veíamos en el apartado anterior, sino también por el pensamiento feminista, que a su vez heredó o se reapropió las categorías de las primeras reflexiones de la antropología cultural anglosajona sobre sexualidad. (MUÑOZ, 1997). A partir de 1983, el PIEM en el Colegio de México; y, desde 1990, el PUEG, en la UNAM; desarrollaron líneas de investigación en torno a la dominación masculina y a la violencia de género, que en los años siguientes integrarían a su vez la perspectiva de los "Men Studies" a través de distintos seminarios, coloquios y publicaciones ${ }^{10}$, en donde, a su vez se consolidó el estudio de varones que mantienen relaciones sexo-afectivas con otros.

No obstante, en comparación con los estudios feministas, las investigaciones sobre las sexualidades minoritarias en centros, programas, seminarios y publicaciones sobre género son mucho más escasas. En "Más de tres décadas de los estudios de género en América Latina", De Barbieri (2004) evidenciaba la poca relevancia de las minorías sexuales en dicho campo: como única referencia acerca de las minorías sexuales, una nota de pie de página precisa que "dentro de la gama de los estudios de la diversidad sexual", no se analizaban las relaciones de poder entre las parejas de varones; mientras que los estudios de masculinidad no habían desarrollado ningún trabajo sobre los efectos de la dominación masculina entre varones heterosexuales u homo/bisexuales. (DE BARBIERI, 2004, p. 210).

Existe, pues, cierta brecha entre el medio académico y la realidad social: mientras que muchos indican una mayor tolerancia hacia las minorías sexuales y la normalización de la homosexualidad - como apuntaban Castañeda (1999) o Miano y Giglia (2001) - todavía la producción académica evidencia el relativo desinterés del medio universitario capitalino por dicho campo de estudio, lo que sugiere la gran dificultad para romper el techo de cristal homofóbico impuesto por años de prejuicios y categorías discriminatorias de la medicina, la criminología y la psicología. Cabe mencionar, además, que el estudio de las minorías sexuales se ha concentrado principalmente en abordar a los varones gays ${ }^{11}$ : el $2 \%$, meramente, de las publicaciones tratan de mujeres bisexuales o lesbianas y el $9 \%$ de personas travestis y transexuales, el $20 \%$ se

10 Por ejemplo, el Seminario de Estudios de la Masculinidad que se efectuó en el PUEG en 1994, o el Seminario de Investigación sobre Violencia Doméstica, del PIEM, a mediados de los años 1990. En el año 1998-1999 se llevó a cabo un Seminario de Antropología de Género en el PUEG y otro Seminario de Diversidad Sexual.

11 Muchos títulos hacen uso de palabras tales como "deseo", "masculinidad" o "varones", que tienden a invisibilizar la identidad sexual de los sujetos: "Sexo entre varones" (NUNEZ, 1991); "El deseo de las sombras" (FELICIANO, 1998); "Dinámica territorial del deseo queer" (López y Sánchez, 2004); "La construcción del deseo" (LAGUARDA, 2004), "La ubicación del deseo" (SÁNCHEZ SUÁREZ, 2012), por ejemplo. Esto, a mi entender, constituye una forma de evitar la reprobación académica. 
enfocan en varones bisexuales; contra un 53\% enfocadas en varones gays, principalmente acomodados ${ }^{12}$.

Por otra parte, mientras que la definición de los sujetos habría cambiado desde una concepción tradicional de la homosexualidad hacia una visión más moderna e igualitaria, tal y como sugiere Laguarda (2009); en buena medida los estudiantes e investigadores siguen entendiendo a las sexualidades periféricas desde el género, y no como deseo, sexo y afecto entre iguales. Así pues, por un lado el estudio de las sexualidades minoritarias queda subsumido al enfoque de género, como si la sexualidad y las minorías sexuales no fueran, en sí y por sí solos, objetos válidos de investigación; mientras que, por otro, la investigación sobre el género se limita con frecuencia al estudio de la violencia y la desigualdad padecidas por las mujeres, sin considerar a los varones, tanto heterosexuales, como bi y homosexuales, como víctimas, también, de la dominación masculina. Como sostiene Scott,

En su acepción reciente más simple, "género" es sinónimo de "mujer". [...]. En algunos casos, esta acepción, aunque se refiera vagamente a ciertos conceptos analíticos, se relaciona realmente con la acogida política del tema. En esas ocasiones, el empleo de "género" trata de subrayar la seriedad académica de una obra, porque "género" suena más neutral y objetivo que "mujeres". [...] Este uso de "género" es una faceta de lo que podría llamarse la búsqueda de la legitimidad académica por parte de las estudiosas feministas en la década de los ochenta. [...]. "Género" como sustitución de "mujeres" se emplea también para sugerir que la información sobre las mujeres es necesariamente información sobre los hombres. (Citado por OROZCO, 2010, p. 119).

Los estudiantes suelen usar el término "masculinidad" para legitimar un objeto de estudio - las relaciones afectivas y sexuales entre personas del mismo sexo y la construcción de identidades sexuales periféricas - todavía no tan institucionalizado como el género. En este sentido, siguen muy presentes algunos prejuicios acerca de las relaciones sexo-afectivas entre personas del mismo sexo, lo que implica entenderlas desde las categorías binarias del sistema tradicional de género, en vez de adoptar una definición moderna, centrada en el/los objeto(s) de deseo del sujeto. Así pues, implícitamente acaban reproduciendo una representación decimonónica de la homo/bisexualidad, como la búsqueda de características del sexo opuesto o como afeminamiento en el caso de los varones. ${ }^{13}$

Esta ausencia de diferenciación analítica entre género y sexualidad, o entre prácticas sexuales e identidades, conlleva una gran confusión entre las y los

12 El $15 \%$ de publicaciones abordan a las minorías sexuales como un conjunto integrado ("LGBTTTI", "disidencia sexual" o "diversidad sexual", por ejemplo.

13 El 'Diccionario del español usual en México', del Colegio de México (1996), define por ejemplo "maricón" como un varón "homosexual", "principalmente él de modales y gustos afeminados". (Citado en CARRIER, 2003, p. 11). 
estudiantes, quienes a veces conciben las prácticas sexuales minoritarias como identidades de género: "Al hablar del género como fundamento y división de lo que entendemos comúnmente como sexualidad, tenemos diferentes perspectivas que tratan de esclarecer los límites, parámetros y connotaciones entre los sexos", explica por ejemplo Camarena (2010, p. 8); mientras que para Elena García (2009) "una de las formas de violencia es la que deriva del sistema de géneros (hombres, mujeres, homosexuales, lesbianas)." "Por ello es fundamental estudiar la violencia que sufren los homosexuales", añade la estudiante, procurando demostrar la relevancia de su objeto de estudio.

\section{El Espacio y las Minorías Sexuales en la Ciudad de México}

\section{Los Estudios Urbanos y las Identidades Sexuales}

Tras haber descrito el panorama de los estudios sobre minorías sexuales en los principales centros universitarios de la ciudad de México, y evidenciar tanto la relativa ausencia de la geografía en este campo hasta fechas muy recientes como la importancia que ha adquirido la categoría "género" para legitimar su objeto de estudio y acercarse al mismo desde los años 90; podemos fijar ahora nuestra atención en la investigación urbana y los acercamientos de la antropología, de la sociología y de las demás ciencias sociales hacia los espacios vividos y percibidos por las minorías sexuales.

Según observábamos en los Gráficos 2 y 3, no es hasta mediados de los 1990 que se empiezan a llevar a cabo investigaciones empíricas sobre los modos de vida y las geografías del encuentro entre varones en la ciudad de México, pero con frecuencia aquéllas fueron realizadas por antropólogos y sociólogos. El interés creciente por la dimensión territorial de los estilos de vida y formas de sociabilidad de las minorías sexuales se percibe en la integración de variables geográficas y dimensiones espaciales, presentes en el $34 \%$ de las referencias de nuestra selección. ${ }^{14}$

En contraste con la importancia que los estudios lésbico-gays publicados en la capital mexicana han otorgado al espacio; los resultados de la búsqueda de referencias acerca de las minorías sexuales en revistas, recopilaciones y revisiones publicadas en el campo de la investigación urbana sobre de la ciudad en México, permiten constatar que, salvo algunas excepciones, aquéllas no fueron mencionadas hasta principios del siglo XXI. En los 60, 70 y 80, los estudios urbanos se centraban principalmente en entender, prever y mitigar los efectos de la urbanización acelerada y los desequilibrios urbanos. (BATAILLON, 1983). Según la revisión de Duhau (1991), en aquellas décadas, los ejes de la investigación urbana eran fundamentalmente tres: políticas urbanas, movimientos sociales y procesos de urbanización. Asimismo, a partir de unos 300 trabajos presentados en el II Congreso de la Red Nacional de Investigación Urbana, de 1997, Duhau enlista los principales temas abordados en el mismo, los más importantes siendo la globalización y la reestructuración espacial; la producción de la ciudad; la crisis medioambiental

14 Nuestra base integró una variable en la que fuimos apuntando, para cada trabajo, la presencia o ausencia de información de tipo espacial. 
y el gobierno en las ciudades así como las identidades locales y los movimientos sociales (DUHAU, 2000).

Por lo tanto, si bien la investigación urbana empezó a integrar la reflexión sobre las identidades, prácticas y representaciones espaciales de los sujetos desde principios de los 90, en México nunca se abordó, hasta fechas recientes, el estudio de las minorías sexuales en sus vínculos con el espacio urbano. En toda la bibliografía consultada, salvo un capítulo de una obra de Gabriel Careaga (1985) sobre la ciudad de México, no se encontraron más que breves referencias en los trabajos de Gomezjara y Canclini acerca de las minorías sexuales y/o de sus espacios de reunión. Fuera de estas escasas referencias, las sexualidades periféricas han sido ausentes de la reflexión sobre segregación, movilidad urbana y ciudad durante más de 40 años.

\section{La Ciudad Enmascarada}

En el Capítulo V de 'La Ciudad Enmascarada', Gabriel Careaga, quien fue catedrático de la UNAM y director de la 'Revista Mexicana de Ciencias Políticas y Sociales', dedicaba un espacio específico a la "gente de noche" (sic) en el que recogía varias historias de vida de personas homosexuales y travestis en la ciudad de México. Se trata de una de las primeras descripciones acerca de los espacios de socialización frecuentados por las minorías sexuales que hayamos podido encontrar en estudios urbanos y revisiones bibliográficas sobre la ciudad de México. Las minorías sexuales son retratadas como personajes de la diversión nocturna: "mientras la ciudad duerme", los que "descansan de día" salen de noche. La "visibilidad homosexual" es ante todo nocturna, vinculada a los establecimientos nocturnos, y opacada por el estigma y la discriminación. El autor recuerda la vistosa presencia de travestis y hombres homosexuales en los cabarets de moda que dieron ritmo a la noche de México entre los años 1920 y finales de los 1940 (Waikiri, Salón México, Ciros, los teatros Tívoli y Lírico), y fueron clausurando, muchos de ellos, durante la regencia de Uruchurtu; si bien precisa que surgieron, después, "otras formas de espectáculo, sobre todo los cafés cantantes, y nuevas formas de prostitución y organización de la vida nocturna”. (CAREAGA, 1985, p. 201).

Para Careaga, si bien desde finales de los 60, nuevamente, "se hace más visible el mundo homosexual, que había sido reprimido y censurado en la ciudad", en dicha época todavía "en términos artísticos, culturales y sociales, el homosexualismo (sic) era tabú" (Careaga, 1985, p. 202) y meramente se describía de manera morbosa en los medios de comunicación. Las representaciones remitían siempre a la "soledad del homosexual" y a formas violentas y clandestinas de socialización y encuentro sexual. Incluso en las primeras manifestaciones LGBT, a finales de los años 70, se veía a las minorías sexuales "con terror, con burla y con desprecio", recuerda Careaga (1985, p. 203).

Careaga asocia el modo de vida homosexual a un tipo de espacio concreto (el establecimiento comercial), una temporalidad específica (la noche), así como unas prácticas marginales, prohibidas y clandestinas, tales como el sexo en público o la prostitución: "Hoy existen en la ciudad muchos centros homosexuales que a mediodía se anuncian como salones para familias y en la 
noche son centros de prostitución". (CAREAGA, 1985, p. 203). El sociólogo describe unas existencias sórdidas, caracterizadas por la soledad, el alcoholismo y el sexo anónimo. La "visibilidad homosexual" se asocia entonces con la marginalidad y la inseguridad. Mediante constantes oposiciones entre la hombría y la feminidad, entre el día y la noche, lo cotidiano y lo espectacular, el sociólogo transmite algunas de las facetas del "ambiente homosexual" en la ciudad de México, remitiéndonos al contexto de represión cotidiana que padecían e internalizaban la mayoría de los varones gays y bisexuales. En cuanto a las mujeres lesbianas, ni siquiera son mencionadas en su obra, lo que atestigua, seguramente, de una invisibilidad aún mayor en su caso.

El autor utiliza la expresión "ghetto gay" para referirse a la concentración en espacios segregados y momentos restringidos de la socialización de los hombres que aman a otros hombres, no sólo para resguardarse de las miradas, sino también "de las redadas; en la calle te llevan por ir abrazado o maquillado. Aquí puede uno hacer lo que quiera, hay protección", tal y como expresa uno de los entrevistados acerca de los primeros lugares de socialización especializado para gente de ambiente. (CAREAGA, 1985, p. 203). La discriminación daría lugar a determinadas formas de socialización y encuentro sexual entre personas del mismo sexo - lo que Careaga denomina "sectarismo" - asociado a la institucionalización de establecimientos comerciales en los cuales el homosexual se sentiría seguro frente al peligro y la discriminación del "mundo exterior". (CAREAGA, 1985, pp. 203-204).

Para definir el crecimiento del ambiente gay como "fenómeno típico de la ciudad", el sociólogo recoge algunas categorías psicoanalíticas, adoptándolas en su análisis de las formas de encuentro homoerótico: el autor diferencia por ejemplo a los "homosexuales" sexualmente "activos" y "machos", quienes llevarían una "vida completamente normal" pese a haber "cambiado de objeto erótico". Algunos "niegan a definirse como homosexuales" y llevan una doble vida o se casan para evitar el estigma. (CAREAGA, 1985, p. 205). El autor liga el "crecimiento" del "homosexualismo" en la ciudad con la mayor competencia masculina y el incremento de la pobreza y desigualdad urbanas: según él, al ser el dinero una manera de ejercer poder, su carencia "puede disminuir la sensación de masculinidad", lo que propiciaría la homosexualidad. (Careaga, 1985, pp. 207-208). Igualmente, la prostitución masculina representaría "una forma compensatoria en demanda de poder" puesto que "el prostituto masculino somete y 'feminiza' a otros hombres débiles", afirmaría incluso Careaga (1985, p. 208).

Si bien su investigación es innovadora en cuanto aporta algunos elementos cruciales para entender los distintos ciclos de presencia pública y represión hacia las minorías sexuales, al esbozar una historia de los espacios de socialización frecuentados por las mismas, o al integrar a unos actores hasta entonces invisibles en los estudios urbanos; sus reflexiones finales reflejan una serie de prejuicios homofóbicos todavía imperantes en el medio académico capitalino. Su enfoque sigue siendo individualista y esencialista, al estar todavía muy influido por la sociología de la desviación, cuyas categorías no son apropiadas para abordar en su complejidad la vivencia de las minorías sexuales respecto de las formas de segregación social y estigma que padecen 
en la ciudad de México.

\section{El Giro Espacial de la Antropología y la Consolidación de un Objeto de Estudio}

Tras este capítulo precursor de Careaga, las primeras etnologías sobre los espacios de socialización y sexo entre varones en la ciudad de México no se realizaron hasta finales de los 90, coincidiendo con la aparición de nuevos enfoques en la investigación del fenómeno urbano en las ciencias sociales, los cuales fueron influenciados por las reflexiones más generales sobre los fenómenos de globalización cultural y económica, que trastocaron los paradigmas estructuralistas en crisis. En efecto, ante los efectos de esta acelerada mundialización, la antropología, entre otras disciplinas, afronta nuevos desafíos, lo que, según presagiaba ya Guillermo Bonfil (1991) poco antes de su muerte, implicaba la necesidad de atender nuevos sujetos y fenómenos en dicha disciplina, así como el abandonar los viejos paradigmas y el "maridaje" de la antropología con el Estado. Según explica el etnógrafo, dicha disciplina, nacida para impulsar el proyecto nacional de la Revolución (BONFIL, 1991, p. 87), debía renovarse y centrarse en los sujetos y sus percepciones, dejando atrás los objetivos ligados a la construcción de una nación uniformada, espacial, ideológica y lingüísticamente.

Aunque en menor medida, la sociología afronta retos parecidos, al abandonarse los enfoques postmarxistas. Identidad, género y cultura se constituyen entonces en las principales categorías para pensar lo urbano (REGUILLO, 1998), mientras que las visiones culturalistas sustituyen los paradigmas marxistas y estructuralistas, cuya crisis en los estudios urbanos y culturales mexicanos fue puesta de relieve por Canclini (1991) y Duhau (1992) desde principios de los 90. Dicho giro espacial de la investigación urbana se traduce por la compilación de Canclini (1995); la publicación, en 'Cuicuilco', de distintos trabajos sobre el concepto del espacio a partir de mediados de los 90; y de una mayor reflexión acerca del habitar y de la vida urbana a raíz de la traducción y publicación de los trabajos de Saskia Sassen (1991) sobre la ciudad global, de Manuel Castells (1995) sobre la ciudad informacional así como de Marc Augé (1992) sobre los "no-lugares" y las identidades urbanas.

Si bien, desde finales de los 80, algunas tesinas de sociología habían integrado variables espaciales - como por ejemplo en Hidalgo, 1988 - no es hasta finales del siglo XX que la centralidad del espacio para el estudio de la sexualidad humana es plenamente reconocida. Desde entonces, la reflexión antropológica acerca de las identidades y los estilos de vida lésbico-gays pondrían énfasis en los aspectos urbanos de la construcción de los mismos. Los primeros artículos sobre la materia fueron publicados en 'Cuicuilco', en un número especial sobre etnologías en la ciudad: "Manhattan, México, dos áreas de encuentro gay" (LIST, 1999) y “Ámbito público y nuevas identidades homosexuales" (SÁNCHEZ, 1999), fueron escritos por estudiantes de la ENAH, quienes adoptan entonces metodologías y categorías de análisis propias a la antropología cultural para abordar los espacios de socialización de los varones gays en la capital del país.

Al iniciar el siglo XXI, constatamos un verdadero "boom" de este tipo de 
investigaciones, al multiplicarse las publicaciones sobre los modos de vida y los espacios de socialización y encuentro sexual de los varones gays: en 1999, List sintetiza su trabajo de tesis sobre espacios de socialización frecuentados por jóvenes gays en Iztapalapa, revista de la UAM-I; y, en 2000, se publica en 'Cuicuilco' un artículo de López y Sánchez, investigadores del Instituto de Investigaciones Geográficas de la UNAM sobre la geografía gay capitalina. Al año siguiente, 'Cuicuilco' $\left(\mathrm{n}^{\circ} 22,2001\right)$ elabora un número especial sobre "Homosexualidades, género y cultura en México", coordinado por Miano y Giglia; y 'Desacatos' edita otro número especial dedicado a las minorías sexuales; ambos con varios artículos sobre los modos de vida y lugares de socialización en la ciudad de México. Porfirio Hernández (2001) y Óscar Gómez (2003) publican sus tesis respectivas sobre la geografía de las homosociabilidades en la capital, y, en 2004, la revista 'Ciudades'. Análisis de la coyuntura y teoría urbana, integraría un número especial $\left(n^{\circ} 62\right)$ sobre "Urbe y Sexualidad", con varios artículos escritos por geógrafos y antropólogos sobre dicha temática.

Así pues, a partir de principios del siglo XXI, la literatura sobre las minorías sexuales ha ido integrando la dimensión cultural y urbana en el estudio de la construcción de las identidades sexuales; y, al revés, la sexualidad surgió entre las temáticas emergentes de la sociología urbana; por un lado, y de la geografía social, por otro. Los autores tratan de aprehender las formas de vivir y expresar los deseos y el amor hacia personas del mismo sexo, así como de estudiar las modalidades en las cuales las minorías sexuales construyen espacios exclusivos. En este sentido, podemos mencionar la tesis de maestría que realizó Ernesto Sánchez (2004) sobre 'Los lugares gays en la Ciudad de México y su relación con la construcción de identidades', en donde el autor presenta mapas que procuran identificar distintos factores socio-geográficos relevantes para la conformación de las identidades sexuales minoritarias.

\section{Tres Ejes para el Análisis del Espacio en la Construcción de las Sexualidades Minoritarias}

Para analizar el lugar del espacio en la bibliografía seleccionada, distinguimos tres ejes de reflexión acerca del papel que aquél desempeña en la construcción de las sexualidades minoritarias. El primero relativo a la geografía de comercios especializados para un público gay, presente en los estudios de Mauricio List (1999, 2000), Porfirio Hernández (2001), Óscar Gómez (2003), Rodrigo Laguarda (2004; 2009), o de Gabriel Gallego (2009), respectivamente antropólogos, historiador y demógrafo; o en las publicaciones de los geógrafos López y Sánchez (2000) o Sánchez Suárez (2004). Estos trabajos evidencian el papel que, desde finales de los 70, ha adquirido el establecimiento comercial en la conformación de identidades homosexuales modernas o gays, al convertirse en una institución central para el encuentro y la socialización de las minorías sexuales: "A principios de los 80 empezaron a gestarse en México espacios inéditos de socialización entre varones homosexuales, en donde fue posible propiciar el reconocimiento recíproco y el sentido de pertenencia a ese colectivo", señalan por ejemplo Miano y Giglia (2001). 
Según algunos autores, esta institucionalización de los establecimientos especializados constituye un indicio de la "liberación homosexual" o de la modernización de la identidad homosexual (LÓPEZ, SÁNCHEZ, 2000; Gómez, 2003; LAGUARDA, 2009; ZARUR, 2010). Sin embargo, dicha asociación entre la liberación gay e incluso el crecimiento de lugares especializados para una asistencia lésbico-gay debe matizarse: antes de existir un movimiento LGBT, tanto en la ciudad de México (CAREAGA, 1985; BOIVIN, 2013) como en Guadalajara (CARRIER, 2003), ya existían lugares mixtos, conocidos y frecuentados por varones que buscaban contactos homosexuales, aunque fueran mixtos, y habían existido lugares exclusivos en los 40 y 50 en la capital. Según afirmaría Carrier (2003 [1995], p. 29), "la carencia de lugares de reunión exclusivos [...] podría atribuirse a la existencia de muchos espacios reservados a hombres y existe por lo tanto la posibilidad de encontrar hombres para relaciones en cualquier sitio para beber de la ciudad".

En la ciudad de México, el surgimiento de espacios identitarios, a finales de los años 70, y su incremento en los 80 , se vinculó con la búsqueda de seguridad ante el riesgo a ser discriminado, agredido, extorsionado $o$ arbitrariamente detenido por los policías. Así, para muchos, "los bares se convirtieron en refugio", constituyendo "una excepción" y otorgando "un respiro" (LAGUARDA, 2004, p. 315). Estos análisis han sido confirmados en otros estudios, que vinculan el auge de espacios comerciales especializados con la discriminación y la violencia que ejercen los policías hacia las minorías sexuales, especialmente las transexuales y travestis que ejercen el trabajo sexual. (BOIVIN, 2014a).

Igualmente, la investigación de Gallego (2010) pone de manifiesto que la importancia de los espacios comerciales en los modos de socialización y encuentro entre varones ha aumentado entre las últimas generaciones, siendo cada vez más preponderante la dupla bar gay/internet como escenarios para conocer parejas del mismo sexo. El demógrafo señala los vínculos de dicha dupla con la "institucionalización de la vida afectivo-erótica mediante la extensión del modelo de pareja gay, incluida su reciente regulación civil". (GALLEGO, 2010, p. 279). Según el demógrafo, "la emergencia, el uso, la apropiación y el desuso de los lugares" sería entonces "el producto de la forma en que la historia social de la ciudad se ha ido configurando una geografía del deseo homoerótico" (GALLEGO, 2010, p. 289), más que el fruto de la liberación homosexual.

Por otra parte, Renaud Boivin (2010) muestra que la evolución de las formas de socialización y de su geografía no supone, en sí, un "progreso" hacia una mayor tolerancia. Según el sociólogo, "la transformación de las relaciones homoeróticas no solo ha tenido efectos diferenciales y graduales según el origen social y étnico [...] sino que la cultura gay, tal y como la entendemos hoy en día, es el resultado de un proceso de distinción, también social [...] de un grupo privilegiado respecto de la fracción popular de la población homosexual y de sus espacios de encuentro" (Boivin, 2010, p. 53). Estos distintos análisis permiten dar cuenta de un proceso de institucionalización de los comercios especializados para la socialización y el encuentro de las minorías sexuales, el cual, sin duda, se halla ligado a la mercantilización del 
ligue homosexual y a la institucionalización del modelo o patrón gay de socialización, inaccesible para muchos.

Ahora bien, para entender las experiencias de los sujetos en relación al espacio urbano, es necesario plantear nuevas preguntas acerca de los espacios comerciales y de sus funciones en la conformación de identidades sexuales. Es menester reflexionar, también, desde las distintas ciencias sociales, sobre los vínculos entre la geografía comercial de encuentro entre pares, la diversificación de las prácticas de las minorías sexuales y las experiencias subjetivas en otros ámbitos geográficos y sociales, tanto domésticos como públicos o comerciales. En este sentido, las prácticas espaciales de los sujetos y los significados que éstos dan en relación a las mismas, deben ser reinterpretados en el contexto metropolitano actual de individualización y fragmentación social; procesos que indirectamente da cuenta la literatura sobre las minorías sexuales.

Según Gallego, por ejemplo, existen todavía cantinas tales como El Oasis y Viena, abiertas a mediados de los años 50 en centro de la ciudad de México, en dónde acuden tanto "afeminados" como varones "vestidos al estilo ranchero", quienes "comparten el mismo espacio, algunos se reconocen gays, pero la mayoría de ellos [...] no se identifica con este 'patrón' [...] y usan otras expresiones para referir su experiencia homoerótica". (GALLAGO, 2010, p. 115). Igualmente, Boivin (2010) elabora distintos tipos ideales de espacios de homo-socialización que van asociados, por una parte, a formas variadas de expresión de la orientación sexual e identidad de género; $\mathrm{y}$, por otra, a variables socio-demográficas tales como el origen social, la ocupación o la edad.

Según argumenta el sociólogo urbano, la configuración de la socialización y el encuentro sexual entre individuos del mismo sexo, a su vez, va cambiando según el lugar geográfico de los establecimientos dentro de la región metropolitana (BOIVIN, 2014b). Por lo tanto, los espacios comerciales no necesariamente se asocian con una identidad sexual concreta (lésbico-gay), sino que su frecuentación implica una combinación de características socioeconómicas y étnicas de los sujetos. En este sentido, los lugares no tienen identidades sexuales - gay, queer, LGBTT - sino que éstas se van conformando en y fuera de los establecimientos comerciales, involucrando tanto el origen socio-geográfico o el lugar de residencia de los actores como sus posibilidades de expresión de su diferencia sexual en el ámbito público, laboral y familiar.

\section{Lo Público y lo Privado o la Visibilidad de la Diferencia Sexual}

El segundo eje identificado en la literatura está ligado a la reflexión sobre la construcción de las fronteras entre lo público y lo privado y la visibilidad social de las identidades y prácticas sexuales minoritarias. Muchos autores hacen referencia al llamado "clóset" para referirse a las estrategias personales que estructurarían la exposición gradual de las minorías sexuales en el espacio público. Los primeros antropólogos extranjeros que realizaron investigaciones acerca de los modos de vida de los homo/bisexuales en la capital mexicana describieron con frecuencia la relativa tolerancia social hacia las muestras de 
afecto entre varones en espacios públicos, lo cual contrastaba con las modalidades de sociabilidad más estrictas existentes en sus países y ciudades de origen. Tanto Clark Taylor (1986) como Ian Lumsden (1991), en sus trabajos realizados en la ciudad de México en los años 70 y 80, constataban en efecto que "In western societies, homosexuals must solve problems of how to recognize one another, meet and socialize while avoiding hostility and punishment. In the United States a preferred approach is to establish exclusive homosexual locales, but in Mexico, interaction problems are solved primarily in heterogeneous situations." (TAYLOR, 1986, p. 117).

Ahora bien, este aspecto ha sido poco abordado por la nueva generación de investigadores, quienes tienden a pensar lo contrario. Algunos autores ponen de manifiesto la existencia de zonas y lugares públicos de socialización y ligue entre varones desde tiempos remotos (BOIVIN, 2013; MACÍAS, 2014; MONSIVÁIS, 2002); mientras que, por otro lado, algunas tesinas y tesis recientes han evocado la importancia de algunos sectores, tales como la Zona Rosa, para la construcción de identidades sexuales minoritarias (LANZAGORTA, 2012; LAGUARDA, 2011). Sin embargo, al suponer que el incremento de establecimientos comerciales simboliza o permite una mayor tolerancia social o visibilidad pública hacia las minorías sexuales, la mayoría de las investigaciones se acercan al papel el espacio desde una visión naturalista, en el sentido apuntado por Kuri (2013).

En su revisión del sentido dado a la relación entre sociedad y espacio en la literatura, la socióloga evidencia que, a menudo, el espacio se da por sentado en vez de considerarse como el producto de las relaciones y de los conflictos sociales (KURI, 2013). Ahora bien, en los trabajos sobre minorías sexuales, la frecuente asociación entre identidad sexual y espacio opaca el conjunto de prácticas y significados que condicionan la experiencia de los lugares; los cuales no se pueden aprehender ni reducir a la cantidad o concentración espacial de los establecimientos comerciales. En este sentido, el estudio de las minorías sexuales debería integrar el análisis del espacio vivido y del espacio percibido por aquéllas para entender los vínculos entre el significado de los lugares, sus usos por los sujetos y las identidades de los mismos, inspirándose en la geografía de género (véase SOTO, 2010).

Algunos investigadores dan cuenta de una doble lógica relacionada con las distintas funciones del espacio público y de los establecimientos comerciales en la biografía y los discursos de los sujetos. Según el estudio de Gabriel Gallego, por ejemplo, los sujetos diferencian entre los lugares comerciales destinados a la socialización y a la diversión, por una parte; los espacios de ligue y sexo, por otra; y, por último, los lugares en los cuales no pueden manifestar sus gustos sexo-afectivos, tales como el ámbito laboral y demás ámbitos heterosexuales (GALLEGO, 2010), convertidos en "lugares prohibidos", por retomar el concepto de Goffman (1963) en su estudio del estigma. Así, según el demógrafo, los lugares de encuentro sexual "constituyen escenarios propicios para la producción de orgasmos, pero no para que tales encuentros se traduzcan en una relación de pareja". (GALLEGO, 2010, p. 260).

Estas dicotomías entre los lugares para el encuentro sexual y los espacios de identidad y diversión; entre éstos últimos y los espacios de prohibición, han 
sido percibidas, también, por algunos geógrafos y sociólogos en Europa (BLIDON, 2008; BOIVIN, 2011; GRÉSILLON, 2000); quienes remiten a los contrastes y conflictos entre los discursos y las prácticas de los sujetos; así como a la influencia de los mismos en la construcción de las fronteras delimitadas. Éstas, a su vez, reflejan las condiciones de discriminación y violencia que muchos sujetos siguen padeciendo en su vida cotidiana: en efecto, asumir una identidad sexual minoritaria de forma pública, en algunos momentos y lugares concretos. Ahora bien, dicho reconocimiento no implica necesariamente un respeto pleno de la preferencia sexual por uno mismo o por los demás, y vice-versa, el cual es imprescindible a la proyección de la existencia social de un grupo o de un sujeto según mostraba Honneth (2010) en su estudio del reconocimiento social.

Aquellas fronteras implican la institucionalización de la segregación y de la exclusión social de las minorías sexuales en muchos ámbitos de la metrópolis, así como la reproducción de una cultura sexual clandestina muy asociada con el riesgo y el peligro. En este sentido, Carrier ya mostraba que el estigma, para los varones homo/bisexuales, conllevaba el uso de espacios más discretos situados en "las afueras de la ciudad, lotes baldíos, edificios desocupados en la ciudad, campanarios de las iglesias, lugares aislados de parques de la ciudad, balcones y baños de los cines, baños de vapores, y autos" (CARRIER, 2003, p. 43), lugares que, en esta época al igual que hoy en día, a menudo se vinculan con un alto riesgo de ser víctima de una agresión física. (BOIVIN, 2014b).

Mientras que las investigaciones actuales se acercan a la construcción de la sociabilidad entre varones homo/bisexuales desde los establecimientos comerciales; los primeros antropólogos insistían en el carácter esencialmente abierto de los espacios públicos en el centro de las principales áreas metropolitanas. Clark Taylor (1978; 1986) y Joseph Carrier (1989) remitían así a la ausencia de establecimientos comerciales y de barrios gays en México para explicar el peso de la socialización de las minorías sexuales en espacios públicos y el relativo margen de tolerancia hacia ellas en los mismos. La progresiva sustitución de los usos tradicionales de los espacios públicos a efectos de ligue y encuentro sexual entre los varones, travestis y transexuales, por establecimientos comerciales especializados o "gay friendly", no constituiría por tanto una evidencia de una mayor apertura hacia las minorías sexuales, sino una manifestación más de la progresiva desaparición del espacio público como lugar de lo común (DUHAU y GIGLIA, 2008; GIGLIA, 2003).

Lo experimentado por las minorías sexuales se halla ligado a la "desestructuración del espacio público" y a las menores posibilidades de convivencia e integración urbana que alimentan los procesos de exclusión y segregación (GIGLIA, 2003: p. 1), lo que afectaría, particularmente, a los grupos minoritarios. En este sentido, varios autores apuntaron que los planes de "revitalización" urbana en el centro de la ciudad de México han tenido como consecuencia, cuando no por objetivo, desplazar a los comerciantes ambulantes, menores de edad en situación de calle y sexoservidores. (TÉLLEZ, 2014). La reflexión sobre la visibilidad pública de los varones gays y bisexuales apunta, pues, la existencia de una acrecentada división espacial que debemos vincular a las formas de producción urbana que se potenciaron desde los 90 en la ciudad neoliberal, y "lo que ellas implican en cuanto a la 
transformación de la relación entre lo público y lo privado y el desarrollo de nuevas formas de división social del espacio urbano" (DUHAU, 2000, p. 20) o para la experiencia del mismo. Según Ángela Giglia (2003, p. 1), en esta ciudad fragmentada, existe una crisis de identificación, "entendida como la imposibilidad de abarcar la ciudad e identificarse con ella como conjunto - de allí la necesidad de recortar pedazos dentro de los cuales reconstruir los vínculos de pertenencia". Esta misma reorganización socio-espacial explicaría, en parte, la metamorfosis actual de la relación entre las prácticas individuales, las identidades sociales y la construcción de los lugares.

\section{Migración, Movimientos Sociales y Cullturas Sexuales}

A menudo la ciudad de México es descrita como un lugar de libertad para la formación y expresión de la diversidad sexual. (MONSIVÁIS, 2002). La capital del país atraería a las minorías sexuales por el anonimato y las oportunidades de encuentro que la vida metropolitana posibilita, al concentrar instituciones urbanas, tales como bares, discos y cafés, que constituyen espacios de construcción y expresión de prácticas e identidades sexuales minoritarias. El "gueto gay", metáfora especial frecuentemente empleada en la literatura en referencia a las formas de socialización de las minorías sexuales y a los fenómenos de exclusión y segregación experimentados por aquéllas (MONSIVÁIS, 2002), habría sido sustituido por un "gueto comercial", producto de la integración entre los objetivos mercantiles y políticos. Zarur señala por ejemplo la existencia una "interconexión" y articulación de "las luchas por los derechos civiles y las mercantiles que se construyen alrededor del gueto, donde unas conllevan al surgimiento de las otras en un proceso contradictorio y paradójico”. (ZARUR, 2010, p. 98). Según él,

Fue en las últimas décadas del siglo pasado que se conforma (sic) propiamente el llamado Movimiento de Liberación Homosexual (MLH), que desde los sesenta contribuyó a que miles de homosexuales dieran la cara y aceptaran $\sin$ (o sin tantas) culpas su orientación sexual. Gays y lesbianas empezaron a salir de los guetos (el gueto es un producto que la homofobia fomenta, aislando a los gays y agrupándolos en espacios marginales), presionando así a mayores márgenes de tolerancia. (ZARUR, 2010, p. 10).

Igualmente, varios trabajos mencionan la existencia de un estilo o modelo de vida común, que surge de la frecuentación del "ambiente" LGBT capitalino. Salvador Cruz, en su estudio sobre las relaciones de pareja entre varones, comenta por ejemplo que entiende al hombre gay en relación a un "estilo particular de vida homosexual", el cual "implica mantener redes sociales con otros homosexuales, compartir una serie de gustos y afinidades, frecuentar ciertos lugares de reunión, emplear determinado lenguaje o formas propias de expresarse" (CRUZ, 2001, p. 114). Igualmente, los trabajos de Laguarda y List se centran en la construcción local de un estilo de vida gay en la ciudad de México, que se confunde con la conformación de una identidad gay 
internacional:

Nos dimos cuenta de que son precisamente las tribus gays, donde se da la socialidad (sic) y consecuentemente, la construcción de elementos culturales que sirven para reproducir la propia preferencia sexual y para dar cuerpo al plano identitario gay, donde se fundan los elementos más positivos de la gaycidad (sic) y donde, por lo tanto, se da la producción y reproducción de la cultura gay. [...]. En México, los adultos gays de los noventa representan a los primeros individuos que han hecho de la gaycidad un estilo de vida. (LIST, 1999, p. VII).

No obstante, si bien la investigación plantea la existencia de estilos de vida ligados a la construcción de las identidades lésbico-gays; el papel de la migración y del origen geográfico y social, en cambio, sigue siendo poco estudiado. La última generación de investigadores ha centrado su interés en el patrón gay, más global, de vida homosexual urbana, mismo que se halla fuertemente ligado a una posición social privilegiada y al mantenimiento del estatus quo en relación al acceso, a los usos y a las limitaciones de los espacios urbanos, sean éstos públicos y mixtos o comerciales y especializados.

Según constata Gallego, mientras que en las clases medias la norma es la no convivencia con la familia de origen y la "preferencia por una ubicación céntrica en algunos arreglos domésticos minoritarios donde habitan hombres solteros" (GALLEGO, 2010, p. 153) que viven solos o con otros hombres; entre los sectores sociales más desfavorecidos, en cambio, las minorías sexuales tienden a residir con sus familias de origen y el acceso al modelo de vida gay se halla restringido, tanto por sus posibilidades económicas más limitadas, como por los lugares de residencia asociados a las mismas, alejados del centro urbano. Boivin (2011) había evidenciado una situación parecida para los jóvenes provenientes de las afueras de la región metropolitana de París.

El demógrafo señala así que el tipo de patrón de corresidencia se asocia "con un buen nivel de empleo e ingresos, ya que habitar en las colonias [de mayor prestigio] requiere dinero y posición que, de no ser heredadas, sólo llegan con los años". (GALLEGO, 2010, p. 153). En cambio, los entrevistados que viven con su familia de origen en general residen en delegaciones periféricas y suelen ser más jóvenes; estudiantes, $\mathrm{u}$ hombres con niveles medios o bajos de instrucción e ingresos. Según concluye el demógrafo, "ambos patrones de construcción de la corresidencia, el céntrico y el periférico, señalan la imbricación entre clase social, edad y estilo de corresidencia" (GALLEGO, 2010, p. 153).

Ahora bien, la gran mayoría de los investigadores se centran en el primer patrón de corresidencia y estilo de vida, sin considerar la desigualdad y la variedad de situaciones entre las minorías sexuales. Además, la última generación de estudiantes y académicos tiende a soslayar que se había consolidado un modo de vida propio mucho antes que la investigación se centrara en esta cuestión, obviando que desde antaño la migración ha sido un factor crucial para la construcción de un espacio de vida ligado a una 
sexualidad minoritaria: así, en sus autobiografías, Elías Nandino y Salvador Novo, respectivamente médico y director de teatro y ambos escritores homosexuales, quienes llegaron a la ciudad de México en los años 20; evidenciaron la existencia de uniones de tipo matrimonial y de redes de ayuda mutua entre varones homo/bisexuales, que más allá del sexo, conformaron una subcultura homosexual, la cual sustituía a la familia de origen para muchos migrantes. (BOIVIN, 2013).

Por lo tanto, antes de los años 60 , los varones homo/bisexuales se reunían en lugares comerciales y privados, organizaban fiestas y habían constituido una red que vinculaba distintos espacios domésticos y públicos, proporcionaba información y permitía la integración social de los nuevos llegados a la ciudad. Ahora bien, pese a existir testimonios en archivos personales y públicos acerca de los modos de vida y formas de corresidencia de las minorías sexuales, así como sobre las estrategias residenciales adoptadas por los migrantes homo/bisexuales al llegar a la ciudad de México; hasta la fecha no se investigó con mayor profundidad los vínculos entre, por un lado, el espacio habitacional, los lugares comerciales y públicos de socialización de las minorías sexuales; y, por otro, los mecanismos de promoción social y ascenso laboral ligados a la consolidación de aquellas redes sociales entre individuos de sexualidades periféricas.

\section{Conclusiones}

Según constatamos, no es sino hasta fechas recientes que el medio académico en la capital mexicana abandonó la perspectiva heterosexista y homofóbica para abordar las sexualidades minoritarias. Mientras que antes de los años 90 la mayoría de los trabajos académicos consideraban a las personas trans/bi/homosexuales como enfermas, delincuentes y marginales; con el surgimiento del VIH/SIDA y la salida del armario de numerosos enfermos en la década siguiente, se comprobó que las tradicionales categorías y perspectivas de análisis provenidas de la criminología y de la psicología clínica eran ineficaces para dar solución al problema de salud pública planteado por la enfermedad, evidenciándose, además, que los bisexuales y homosexuales eran más numerosos de lo que se pensaba. Si bien la mayor información sobre el VIH supuso, para muchos, el fortalecimiento del llamado "clóset" individual, debido al doble estigma y al refuerzo de la asociación entre sexualidad minoritaria y enfermedad; por otro lado obligó a cambiar las perspectivas hasta aquel momento predominantes en las instituciones académicas acerca de las minorías sexuales: de ahí, sin duda, la renovación de las estrategias y enfoques para tratar de las sexualidades periféricas.

Por otra parte, las reflexiones feministas sobre lo público y lo privado, la institucionalización de los estudios de género; junto con la crisis y el abandono de los paradigmas individualistas, cuantitativos y marxistas, obligaron a abordar las sexualidades minoritarias desde las representaciones y discursos de los propios sujetos, desde sus cotidianidades; entendiéndose entonces su marginalización como el producto de una construcción ideológica, social y cultural ligada al sistema tradicional de género. Aún, así, incluso en la 
actualidad, persisten algunos prejuicios, preceptos y enfoques que impiden el reconocimiento pleno de las minorías sexuales como objeto de estudio válido y legítimo.

Por último, el giro espacial de las ciencias sociales - especialmente de la antropología - tuvo por consecuencia la mayor atención, en las mismas, hacia los modos de vida, espacios de socialización y construcción identitaria de las minorías sexuales: si bien la geografía y los estudios urbanos incorporaron la investigación sobre éstas de forma tardía, fueron cada vez más frecuentes los trabajos de antropología y sociología sobre identidades y prácticas sexuales minoritarias que utilizaron categorías espaciales y se centraron en factores geográficos para aprehender y estudiar la conformación social - local - de las sexualidades minoritarias. La revisión bibliográfica que presentamos permite constatar, no obstante, que a menudo el concepto de espacio no ha sido discutido o integrado sino de manera teórica y esencialista en los estudios sobre minorías sexuales. En buena medida, el estudio del papel del espacio en la construcción de los significados, prácticas e identidades de los sujetos se redujo a la reflexión sobre los establecimientos comerciales orientados hacia las minorías sexuales, dedicándose poca atención a los ámbitos laborales y habitacionales, así como a la experiencia de los sujetos en relación al resto de los espacios urbanos.

Ahora bien, para entender el rol que desempeña el espacio para la construcción de las sexualidades minoritarias o para la reproducción del estigma y de la discriminación hacia las minorías sexuales, éste debe ser pensado desde sus diversas dimensiones, tanto materiales como simbólicas, lo que implica "aproximarse al análisis del espacio desde la interdisciplinariedad, obligando al científico social a depurar sus conceptos y métodos de estudio" (KURI, 2013, p. 71). En este sentido, se necesita un mayor desarrollo de los estudios empíricos sobre el espacio vivido y percibido por minorías sexuales, las vivencias y representaciones de éstas en relación al mismo; así como acerca de los vínculos entre la consecución de derechos sociales y cívicos, por un lado, y el desarrollo de un mercado para el sector LGBT, por otro.

Pese a la mayor atención hacia la construcción socio-histórica y cultural de las sexualidades periféricas en las ciencias sociales, y a la multiplicación de las referencias sobre los espacios de socialización, encuentro y sexo entre las minorías sexuales en la ciudad de México, quedó por integrarse de forma más sistemática el análisis de las interacciones entre los factores socio-culturales y económicos locales que intervienen en la formación de las identidades sexuales, la consolidación de espacios especializados e identificables para las minorías sexuales, y el contexto en los cuales aquellas identidades se van produciendo, reproduciendo y modificando.

Por una parte, la geografía cuantitativa, centrada en la concentración espacial de establecimientos comerciales, no nos permite abordar las formas de apropiación y vivencias de los individuos; mientras que por otra parte las demás disciplinas científicas que integraron la problemática del espacio urbano y de las minorías sexuales no dedican todavía la atención necesaria a los procesos metropolitanos y locales que afectan y condicionan los modos de vida, las formas de habitar, la movilidad urbana y la participación de las 
minorías sexuales en la vida pública. Sin duda, el desarrollo del comercio dirigido hacia las minorías sexuales ha contribuido a la visibilidad, el reconocimiento y a la integración de éstas; pero es menester entender que el espacio vivido de las minorías sexuales no se limita a la geografía de los lugares comerciales; para volver a centrar la investigación hacia los espacios residenciales y las formas de discriminación y violencia que condicionan el uso y disfrute de la ciudad en su conjunto.

Por lo tanto, es necesario reconstruir los distintos mecanismos que engendran la exclusión de las minorías sexuales, impiden su participación plena en la vida social, política y económica en todos los ámbitos sociales y sectores geográficos de la ciudad de México. De no ser así, los académicos que estudian los vínculos entre sociedad y espacio, entre sexualidades minoritarias y aceptación social, no harían sino opacar las realidades y problemáticas vividas y padecidas por los sujetos. En este sentido, la apertura actual del medio académico en la capital mexicana debe ser aprovechada para entender con mayor profundidad las distintas limitaciones al derecho de las minorías sexuales a la ciudad y buscar las formas y maneras de reducir la segregación espacial y exclusión social de éstas.

\section{Referencias ${ }^{15}$}

BARRANCO LAGUNAS, María Isabel. Análisis pragmático discursivo de las revistas lésbico-feministas Las amantes de la luna, 1993-2003, Lesvoz, 1996-2004 y Nota'n Queer, 2002-2004. 2008. Tesis (Doctorado en Ciencias Sociales con Especialidad en Mujer y Relaciones de Género) - Universidade Autónoma Metropolitana, Ciudad de México.

BATAILlON, Claude. Dos décadas de investigación urbana. Estudios Sociológicos, v. 1, n. 1, p. $151-160,1983$.

BARRALES RIVAS, Edgar Omar. Las desviaciones sexuales como causal de divorcio en el Código civil para el Distrito Federal. 2005. Tesis (Licenciatura en Derecho) - Universidad Nacional Autónoma de México, Ciudad de México.

BLIDON, Marianne. Jalons pour une géographie des homosexualités. L'Espace géographique, v. 37, n. 2, p. 175 - 189, 2008.

BOIVIN, Renaud. De la ambigüedad a la sobrevisibilidad: homosexualidad, género y espacio en la Ciudad de México. Ciudades, Análisis de la coyuntura, teoría e historia urbana, número especial "Ciudad y Género", n. 88 , p. $52-59,2010$.

15 Debido a la consulta de una gran cantidad de publicaciones para la realización de este trabajo, solamente se menciona en la bibliografía final las que hayan sido directamente citadas, salvo que la referencia haya marcado de forma particular los estudios sobre minorías sexuales y la geografía de género en México. 
BOIVIN, Renaud. Entre agrégation et ségrégation, les gays en région francilienne. Justice Spatiale / Spatial Justice. n. 3, p. 1 - 12, 2011.

BOIVIN, Renaud. De cantinas, vapores, cines y discotecas. Cambios, rupturas e inercias en los modos y espacios de homosocialización de la ciudad de México. Revista Latinoamericana de Geografía y Género, v. 4, n. 2, p. 118 133, 2013.

BOIVIN, Renaud. La ciudad de la homofobia. Discriminación y violencia hacia las minorías sexuales en las urbes mexicanas. Revista Latinoamericana de Geografía y Género, v. 5, n. 1, p. 180 - 207, 2014a.

BOIVIN, Renaud. L'organisation sociale et spatiale des identités homosexuelles à Mexico. Construction d'une économie culturelle au cours du XXème siècle. Métropoles, n. 14, p. 1 - 29, 2014 b.

BONFIL BATALLA, Guillermo. Desafíos a la antropología en la sociedad contemporánea. Iztapalapa, Revista de Ciencias Sociales y Humanidades, n. 24, p. $77-92,1991$.

CAMARENA LÓPEZ, César. El Uso de internet como medio de contacto entre los Gay's para sus prácticas sexuales. 2010. Tesis (Licenciatura en Psicología) - Universidad Nacional Autónoma de México, Ciudad de México.

CAREAGA, Gabriel. La ciudad enmascarada. México: Plaza y Janes, 1985.

CARRIER, Joseph. Gay Liberation and Coming out in Mexico. Journal of Homosexuality, v. 17, n. 3 - 4, p. 225 - 252, 1989.

CARRIER, Joseph. De los otros. Intimidad y homosexualidad entre los hombres del occidente y el noroeste de México. Nueva York: Columbia University Press, 2003 [1995].

CARRILLO, Héctor. La noche es joven. La sexualidad en México en la era del sida. México: Ediciones Océano, 2002 [1996].

CRUZ SIERRA, Salvador. La pareja gay en México: algunos indicadores. Cuicuilco, v. 8, n. 23, p. 113 - 125, 2001.

DÍAZ BARBER DEL TORO, Ana Belén. Multiculturalismo. La cultura Lésbica-Gay como minoría y parte de nuevos movimientos sociales. 2001. Tesis (Licenciatura en Ciencias Políticas) - Universidade Autónoma Metropolitana, Ciudad de México.

DE BARBIERI, Teresita. Más de tres décadas de los estudios de género en América Latina. Revista Mexicana de Sociología, v. 66, p. 197 - 214, 2004.

DUHAU, Emilio. La sociología y la ciudad. Panorama y perspectivas de los estudios urbanos en los años ochenta. Sociológica, v. 5, n. 12, s/p, 1991. 
DUHAU, Emilio. Ciencias sociales y estudios urbanos: ¿adiós a los paradigmas?. Sociológica, v. 7, n. 18, p. 29 - 43, 1992.

DUHAU, Emilio. Estudios urbanos: problemas y perspectivas en los años noventa. Sociológica, v. 15, n. 42, p. $13-35,2000$.

FELICIANO, Omar. EI deseo en las sombras, estudio exploratorio sobre cuartos obscuros y el proceso de salud-enfermedad del SIDA en la comunidad gay. 1998. Tesis (Licenciatura en Psicología) - Universidade Autónoma Metropolitana, Ciudad de México.

GALLEGO MONTES, Gabriel. Demografía de lo otro. Biografías sexuales y trayectorias de emparejamiento entre varones en la Ciudad de México. México: El Colegio de México, 2010.

GARCÍA ALFARO, María Lorena. Violencia hacia los homosexuales en el Distrito Federal. 2009. Tesis (Licenciatura en Sociología) - Universidade Autónoma Metropolitana, Ciudad de México.

GARCÍA CANCLINI, Néstor. Los estudios culturales de los 80 a los 90: perspectivas antropológicas y sociológicas en América Latina. Iztapalapa, Revista de Ciencias Sociales y Humanidades, n. 24, p. 9 - 26, 1991.

GARCÍA MURCIA, Miguel et al. Memoria de la lucha contra el VIH en México. Los primeros años. México: CONAPRED, Historiadores de las Ciencias y las Humanidades A.C. 2010.

GIGLIA, Ángela. Espacio público y espacios cerrados en la Ciudad de México. En: KURI RAMÍREZ, Patricia (Coord.), Espacio público y reconstrucción de ciudadanía. México: FLACSO-Porrúa, 2003.

GONZÁLEZ PÉREZ, María Jesús. La construcción del imaginario social, análisis de los discursos de la Iglesia Católica y de los movimientos homosexuales. 2002. Tesis (Maestría en Sociología) - Universidade Autónoma Metropolitana, Ciudad de México.

GRÉSILLON, Boris. Faces cachées de l'urbain ou éléments d'une nouvelle centralité? Les lieux de la culture homosexuelle à Berlin. L'Espace géographique, v. 29, n. 4, p. $301-313,2000$.

HEREDIA CARRILLO, Nelly Noemí. El psicodiagnóstico de Rorschach como detector de la homosexualidad. 1966. Tesis de Licenciatura en Psicología. Facultad de Psicología, UNAM, México.

HERNÁNDEZ CABRERA, Porfirio. No nacimos ni nos hicimos, solo lo decidimos: construcción identidad gay en grupo UNIGAY de la ciudad de México. 2002. Tesis (Maestría en Antropología Social) - National School of Anthropology and History, Ciudad de México.

HIDALGO SÁNCHEZ, Francisco Manuel. Aspectos sociológicos sobre la 
homosexualidad en la ciudad de México. 1988. Tesis (Licenciatura en Sociología) - Universidade Autónoma Metropolitana, Ciudad de México.

LAGUARDA, Rodrigo. La emergencia de los bares gay en la ciudad de México: el espacio como generador de identidad. En: COLLADO HERRERA, María del Carmen (Coord). Miradas recurrentes, La ciudad de México en los siglos XIX y XX, Tomo II, México, Instituto Mora/UAM-A, 2004, p. 311 319.

LAGUARDA, Rodrigo. Ser gay en la ciudad de México. Lucha de representaciones y apropiación de una identidad, 1968-1982. México: Instituto Mora/CIESAS, 2009.

LANZAGORTA GARCÍA, José Ignacio. Crear un "si lugar"; estudio socioespacial de la Glorieta de los Insurgentes en la ciudad de México. 2012. Tesis (Maestría en Antropología Social) - Universidad Iberoamericana, México.

LIGUORI, Ana Luisa. Las investigaciones sobre bisexualidad en México. Debate Feminista, v. 6, n. 11, p. 132 - 156, 1995.

LIST REYES, Mauricio. Jóvenes corazones gay en la cd de México: género identidad y socialidad en hombres gay. 2000. Tesis (Maestría en Antropología Social) - Escuela Nacional de Antropología e Historia, Ciudad de México.

LÓPEZ LÓPEZ, Álvaro; SÁNCHEZ CRISPIN, Álvaro. Visión geográfica de los lugares gay en la Ciudad de México. Cuicuilco, v. 7, n. 18, p. 1 - 16, 2000.

MARTÍNEZ NÚÑEZ, David. Es Verano y el Arcoiris ya Pasó: Relato Periodístico de la XXXI Marcha del Orgullo LGBTT de la Ciudad de México del año 2009. 2012. Tesis (Licenciatura en Periodismo) - UNAM, México.

MIANO, Marinella; GIGLIA, Ángela. Identidades en construcción y deconstrucción: una exploración del archipiélago lésbico-gay desde la historia oral. Cuicuilco, v. 8, n. 22, p. 67 - 96, 2001.

MONSIVÁIS, Carlos. Los gays en México: la fundación, la ampliación y la consolidación del ghetto. Debate Feminista. v. 13, n. 26, p. 89 -115, 2002.

MOGROVEJO, Norma. Un amor que se atrevió a decir su nombre: la lucha de las lesbianas y su relación con los movimientos homosexual y feminista en América Latina. 1988. Tesis (Doctorado en Estudios Latinoamericanos) UNAM, México.

MUÑIZ, Elsa. De la cuestión femenina al género: un recorrido antropológico. Nueva Antropología, v. XV, n. 51, p. 119 - 131, 1997.

NAVARRETE FERNÁNDEZ, Gabriel. La inserción del homosexual en la 
cotidianidad social mexicana. 1997. Tesis (Licenciatura en Sociología) UNAM, México.

OROZCO RAMÍREZ, Mariana. Salud reproductiva, género y sexualidad en la investigación mexicana de corte antropológico (1995-2005). Alteridades, v. 20, n. 40, p. 109 - 139, 2010.

PARKER, Richard. Sexualidad, cultura y poder en la investigación sobre VIH/Sida. Casa del Tiempo, n. 29, p. 86 - 96, 2010.

KURI PINEDA, Edith Elvira. Representaciones y significados en la relación espacio-sociedad: una reflexión teórica. Sociológica, v. 28, n. 78, p. 69 - 98, 2013.

RAMOS FRÍAS, José Antonio. Estudio criminológico y médico legal de la homosexualidad. 1966. Tesis (Doctorado en Criminología) - UNAM, México.

REGUILLO, Rossana. Cultura y territorio, identidades locales y regionales y modos de vida. Ciudades. Análisis de la coyuntura, teoría e historia urbana, n. 37, p. $51-52,1998$.

RIVERA ZAYAS, Aristeo. La homosexualidad masculina: revisión bibliográfica de algunos aspectos clínico-sociológicos. 1975. Tesis (Licenciatura en Psicología) - UNAM, México.

SANDOVAL FREGOSO, Eloísa. La homosexualidad como fenómeno social: marginación y actitud de rechazo social. 1990. Tesis (Licenciatura en Sociología) - UAM-I, México.

SÁNCHEZ HUESCA, Ricardo. La homosexualidad masculina: revisión de aspectos biosociales y psicológicos. 1970. Tesis (Licenciatura en Psicología) UNAM, México.

SOTO VILLAGRÁN, Paula. La ciudad pensada, la ciudad vivida, la ciudad imaginada: Reflexiones teóricas y empíricas. La Ventana, Revista de estudios de género, v. 4, n. 34, p. 7 - 38, 2011.

SUÁREZ SÁNCHEZ, Ernesto Rafael. Lugares gays en la Ciudad de México y su relación con la construcción de identidades. 2004. Tesis (Maestría en Geografía) - UNAM, México.

TAYLOR, Clark. How Mexicans Define Male Homosexuality: Labeling and the Buga View". Kroeber Anthropological Society Papers, n. 53 - 54, p. 106 $-128,1975$.

TAYLOR, Clark L. Mexican Male Homosexual Interaction in Public Contexts. Journal of Homosexuality, v. 11, n. 3 - 4, p. 117 - 136, 1986.

TÉLLEZ CONTRERAS, León Felipe. La revitalización del Centro Histórico de la Ciudad de México: entre la voluntad de la élite y la realidad del pueblo. 
Las Minorías Sexuales y la Investigación Urbana en la Ciudad de México

(1960-2013)

Pacarina del Sur, n. 22, s/p, 2015.

VANCE, Carol. La antropología redescubre la sexualidad: un comentario teórico. Estudios Demográficos y Urbanos, v. 12, n. 1/2, p. 101-128, 1997.

ZARUR OSORIO, Antonio. El emergente mercado gay: el caso del Cabaretito. Idónea comunicación de resultados. 2010. Tesis (Maestría en Estudios Organizacionales) - UAM-X, México. 